\title{
EBSD Study on the Effect of a Strong Axial Magnetic Field on the Microstructure and Crystallography of Al-Ni Alloys During Solidification
}

\author{
XI LI, YVES FAUTRELLE, ANNIE GAGNOUD, RENE MOREAU, DAFAN DU, \\ ZHONGMING REN, and XIONGGANG LU
}

The effect of a strong magnetic field on the microstructure and crystallography of the primary and eutectic $\mathrm{Al}_{3} \mathrm{Ni}$ phases in Al-Ni alloys was investigated by using EBSD. The results show that the magnetic field significantly affected the microstructures and crystallography during both volume and directional solidification. As a result, the $\mathrm{Al}_{3} \mathrm{Ni}$ primary phases were aligned with the $\langle 001\rangle$ crystal direction along the magnetic field and formed a layer-like structure. The magnetic field intensity, solidification temperature, growth speed, and alloy composition played important roles during the alignment process of the $\mathrm{Al}_{3} \mathrm{Ni}$ primary phase. Indeed, the alignment degree increased with the magnetic field and the solidification temperature during normal solidification. Moreover, the effect of the magnetic field on the crystallography of the $\mathrm{Al}-\mathrm{Al}_{3} \mathrm{Ni}$ eutectic in the $\mathrm{Al}-\mathrm{Ni}$ alloys was also studied. The applied magnetic field modified the orientation of the preferred growth direction of the $\mathrm{Al}_{3} \mathrm{Ni}$ eutectic fiber and the crystallographic orientation relationship of the $\mathrm{Al}-\mathrm{Al}_{3} \mathrm{Ni}$ eutectic. The orientation of the preferred growth direction of the $\mathrm{Al}_{3} \mathrm{Ni}$ eutectic fiber depended mainly on the solidification direction and the alignment of the $\mathrm{Al}_{3} \mathrm{Ni}$ primary phase. Furthermore, a method for controlling the crystallization process by adjusting the angle between the solidification direction and the magnetic field was proposed.

\section{INTRODUCTION}

DUE to the recent development of superconducting technology, a strong magnetic field with a relatively wide spatial extent has become easy to produce. The application of a strong magnetic field has attracted much attention in the area of electromagnetic material processing, and many new phenomena and functions have been observed. The alignment of non-magnetic materials during several processes has been examined, such as solidification, electro-deposition, vapor-deposition, and solid-phase reactions. ${ }^{[1-5]}$ Experimental research has demonstrated that a strong magnetic field significantly affects the solidification of materials. Mikelson and Karklin ${ }^{[6]}$ obtained an aligned solidification structure in $\mathrm{Al}-\mathrm{Cu}$ and $\mathrm{Cd}-\mathrm{Zn}$ alloys in a $1.5 \mathrm{~T}$ magnetic field. Savitsky ${ }^{[7]}$ found that the MnBi phase in Bi-Mn alloy aligned along the magnetic field direction during the solidification of the alloy. Rango ${ }^{[8]}$ extended this

XI LI, Professor, is with the State Key Laboratory of Advanced Special Steels, Shanghai University, Shanghai, 200072, P.R. China, and also with the SIMAP-EPM-Madylam/G-INP/CNRS, PHELMA, BP 75, 38402 St Martin d'Heres Cedex, France. Contact e-mail: 1x_net@sina.com YVES FAUTRELLE, ANNIE GAGNOUD, and RENE MOREAU, Professors, are with the SIMAP-EPM-Madylam/ G-INP/CNRS. ZHONGMING REN and XIONGGANG LU, Professors, and DAFAN DU, Ph.D. Student, are with the State Key Laboratory of Advanced Special Steels, Shanghai University, Shanghai. investigation to the solidification of paramagnetic $\mathrm{YBa}_{2} \mathrm{Cu}_{3} \mathrm{O}_{7}$ material and obtained a texture crystal structure in a magnetic field. Katsuk ${ }^{[9]}$ reported that diamagnetic benzophenone crystallized from $n$-hexane and $\mathrm{KCl}$ and that $\mathrm{BaCl}_{2}$ crystallized from a solution aligned in a magnetic field of $10 \mathrm{~T}$. This alignment behavior has been investigated intensively. ${ }^{[10-12]}$ Asai $^{[10]}$ observed perpendicular alignment in Al-Si-Fe alloy during solidification in a strong magnetic field. The textured crystal growth of $\mathrm{Bi}-2201^{[11]}$ and $\mathrm{Bi}(\mathrm{Pb}) 2212^{[12]}$ has also been observed in a strong magnetic field. Moreover, in a sufficiently strong magnetic field, the nucleation, ${ }^{[13]}$ surface tension, ${ }^{[14]}$ and even the diffusion of atoms ${ }^{[15]}$ can be influenced. Therefore, the effect of a strong magnetic field on alignment/growth during solidification presents itself with a large degree of complexity.

It is well known that a magnetic field is always applied to damp convection during directional solidification. In recent studies, thermoelectric magnetic effects on solidification structures have been investigated in detail, ${ }^{[16-18]}$ and thermoelectric magnetic effects have been observed to affect the solidification structure remarkably. However, there are few studies that have investigated, in detail, the effect of a magnetic field on the microstructure and crystallography of the primary and eutectic $\mathrm{Al}_{3} \mathrm{Ni}$ phases in $\mathrm{Al}-\mathrm{Ni}$ alloys during both volume and directional solidification. In previous studies, ${ }^{[19,20]}$ the effects of a strong magnetic field on the growth of $\alpha$-Al and $\mathrm{MnBi}$ crystals in directionally solidified Al-4.5wtpctCu and Bi-0.82wtpctMn alloy have been studied. It has been observed that an axial magnetic field causes the 


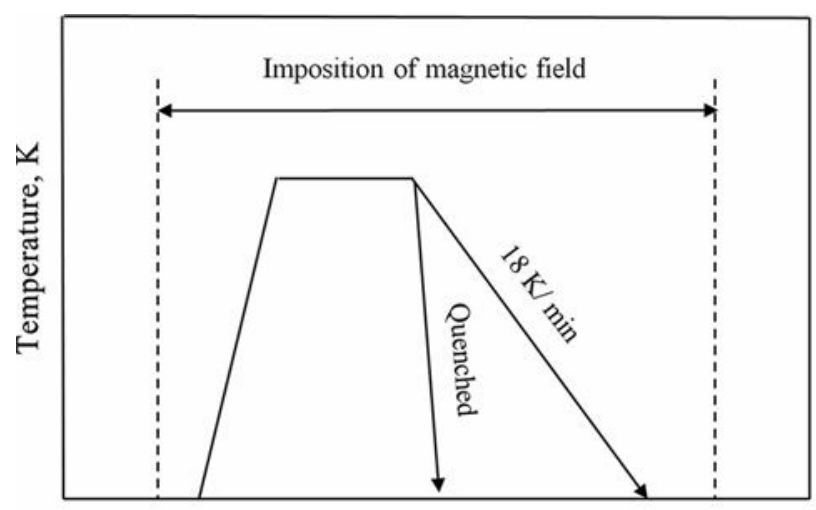

Time, $\min$

(a)

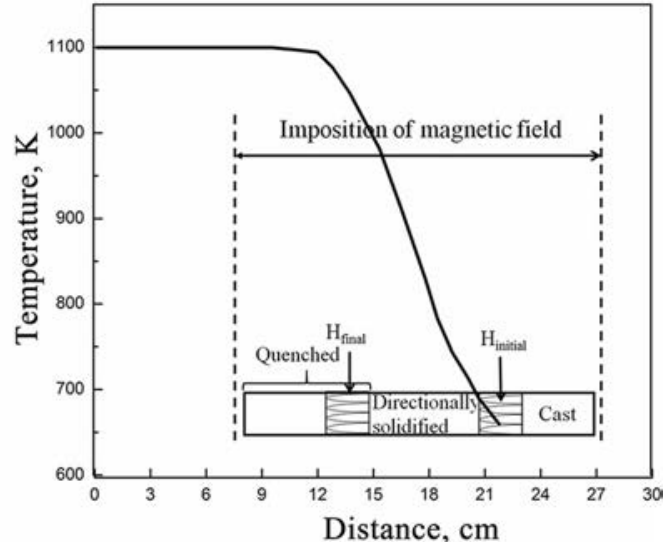

(b)

Fig. 1-Temperature profiles for the solidification procedure: (a) Temperature profiles during normal solidification; (b) temperature profiles during directional solidification.

$\langle 111\rangle$ crystal direction of the $\alpha$-Al crystal to orient along the solidification direction instead of the $\langle 100\rangle$ crystal direction and to enhance the growth of MnBi fibers. In the present study, the effect of a strong magnetic field on the microstructure and crystallography of Al-Ni alloys during the solidification process was investigated. This directional and normal solidification was also investigated in detail using EBSD technology.

\section{EXPERIMENTAL}

The Al-Ni eutectic and the four hypereutectic Al-Ni alloys containing 10,12,15, and $30 \mathrm{wt}$ pct nickel used in this study were prepared with high-purity Al (99.999 wt pct) and $\mathrm{Ni}$ (99.99 wt pct) in an induction furnace. The alloy, after being placed in a high-purity graphite crucible with a $10-\mathrm{cm}$ diameter, was heated to $1173 \mathrm{~K}$ $\left(900{ }^{\circ} \mathrm{C}\right)$, magnetically stirred for 0.5 hour, and poured into a graphite mold to cast the samples. The cast samples were enveloped for normal solidification in a high-purity corundum tube with an inner diameter of 8 $\mathrm{mm}$ and a length of $30 \mathrm{~mm}$. The cast samples were enveloped for directional solidification in a high-purity corundum tube with an inner diameter of $3 \mathrm{~mm}$ and a length of $200 \mathrm{~mm}$.

The experimental set-up for the normal solidification under a strong axial magnetic field consisted of a superconductor magnet, a water-cooling cover, a heating furnace, and a temperature-control system. The superconducting magnet can produce an axial static magnetic field with an intensity that can be adjusted to up to $14 \mathrm{~T}$. In this magnet, there is a uniform magnetic field in an 8-cm zone in the center of the magnet. The experimental set-up for directional solidification under an axial strong magnetic field was described in Reference 21. The set-up is composed of a static superconducting magnet, a Bridgman-Stockbarger-type furnace, and a growth-velocity and temperature controller. The furnace, consisting of non-magnetic material, has a negligible effect on the field uniformity. The temperature in the furnace can reach $1873 \mathrm{~K}$ $\left(1600{ }^{\circ} \mathrm{C}\right)$ and is controlled with a precision of $\pm 1 \mathrm{~K}$. A water-cooled cylinder containing liquid Ga-In-Sn metal (LMC) is used to cool the sample. Adjusting the temperature of the furnace, hot zone, which is insulated from the LMC by a refractory disk, controls the temperature gradient in the sample. To perform directional solidification, the apparatus is designed such that the sample moves downward, while the furnace remains fixed. In the experiments conducted in this study, the samples in the corundum crucibles were placed at the center of the magnet, and the liquid/solid interface of the samples was placed in the uniform magnetic field. Then, the samples were melted and directionally solidified in the Bridgman apparatus by pulling the crucible assembly into the LMC cylinder at various speeds. Figures 1(a) and (b) shows temperature profiles for normal solidification and directional solidification procedure, respectively.

The samples obtained from the experiment were cut along the direction parallel to the magnetic field or in the solidification direction. After machining off the surface, the longitudinal (parallel to the magnetic field direction or the solidification direction) microstructures were examined in the etched condition by optical microscopy and scanning electron microscopy (SEM). Moreover, the crystallographic characteristics were investigated using electron back-scattered diffraction (EBSD) in a high-resolution scanning electron microscope equipped with an EDAX OIM EBSD Analysis System. The EBSD data were rotated by $90 \mathrm{deg}$ around the reference direction (RD) to transform the data into a more familiar reference frame with the normal direction (ND) along the magnetic field or the solidification direction.

\section{RESULTS}

\section{A. Effect of a Magnetic Field on the $\mathrm{Al}_{3} \mathrm{Ni}$ Primary Phase During Normal Solidification}

Figure 2 shows the EBSD maps and the corresponding pole figures for the structures in Al-10wtpctNi 
alloy solidified from $1023 \mathrm{~K}\left(750^{\circ} \mathrm{C}\right)$ (melting state) at a cooling rate of $18 \mathrm{~K} / \mathrm{min}$ under various magnetic fields. In the case in which no field was applied, the structures of the alloy showed a typical disordered nature. However, after the application of a magnetic field, the $\mathrm{Al}_{3} \mathrm{Ni}$ phases gradually aligned with the increase in the magnetic field. As a consequence, the plane of the $\mathrm{Al}_{3} \mathrm{Ni}$ primary phase was perpendicular to the magnetic field direction when the magnetic field reached $1 \mathrm{~T}$. Along with the alignment of the $\mathrm{Al}_{3} \mathrm{Ni}$ primary phase, the $\langle 001\rangle$ crystal direction of the $\mathrm{Al}_{3} \mathrm{Ni}$ crystal was oriented along the magnetic field. Figure 3

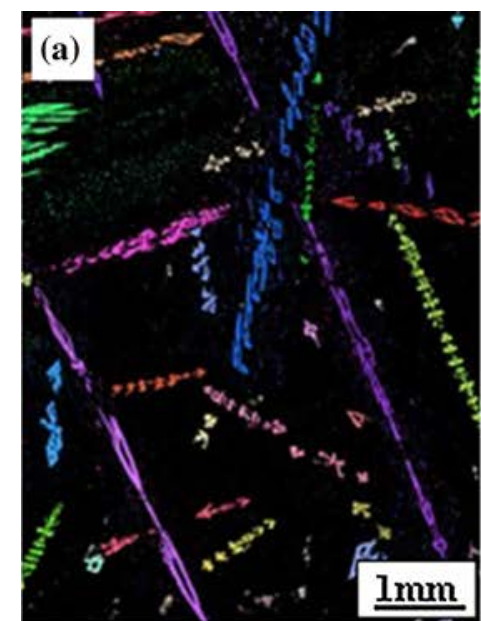

[001]

010
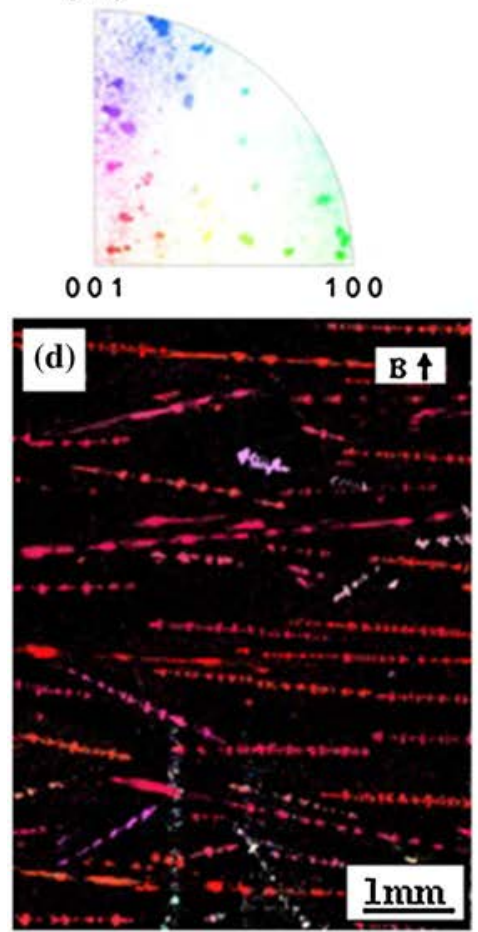

[001]

010

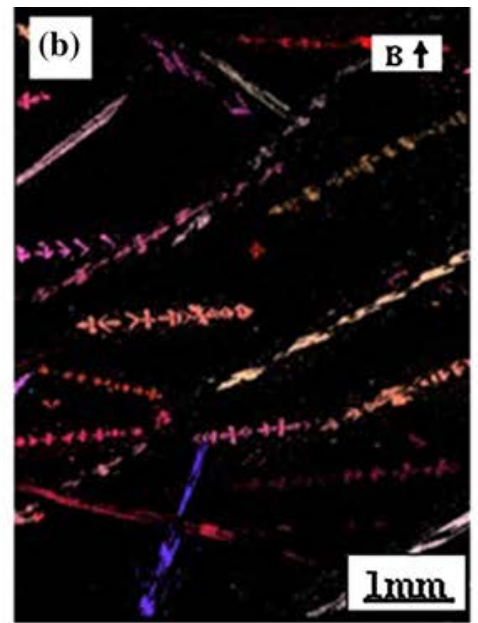

[001]

010
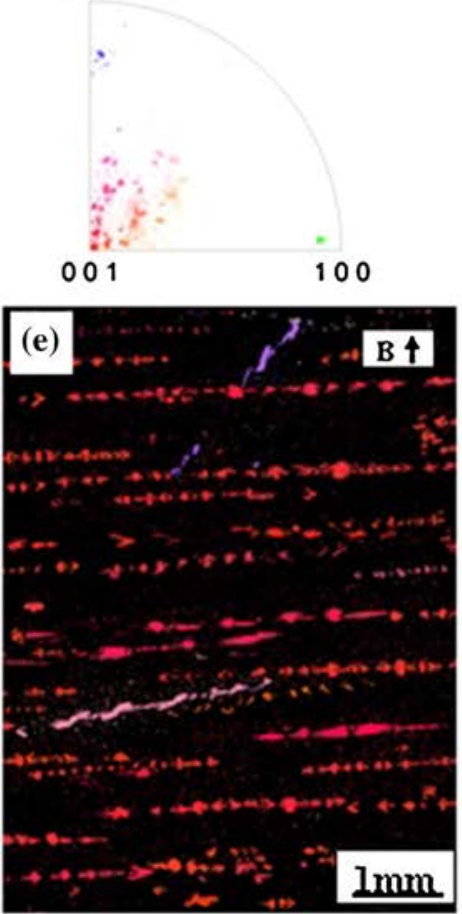

[001]

010

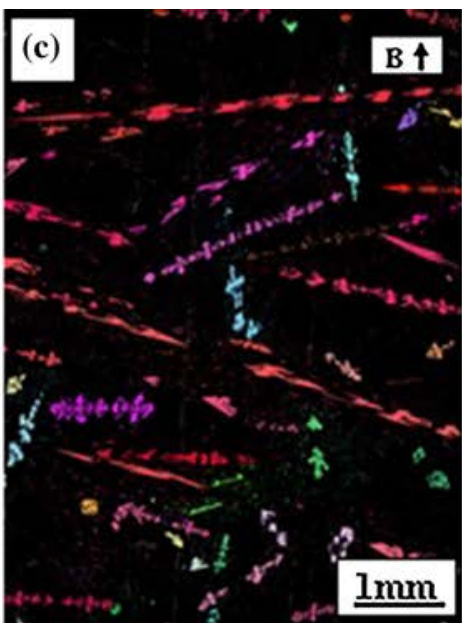

[001]

\section{0}

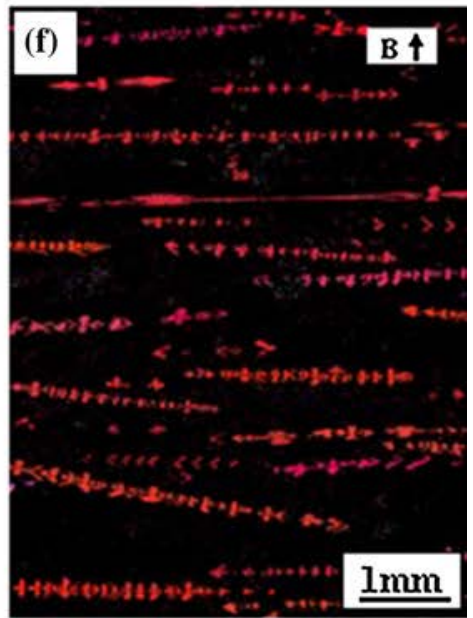

[001]

010
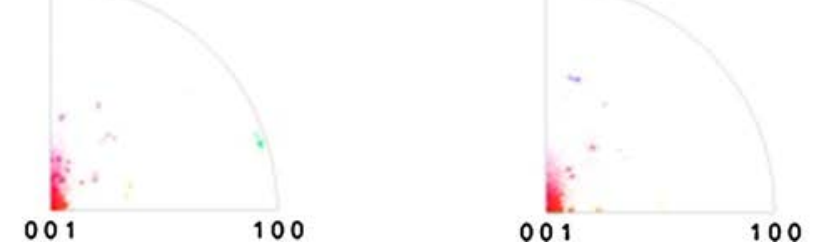

100

Fig. 2-EBSD maps and the corresponding pole figures for the $\mathrm{Al}_{3} \mathrm{Ni}$ phases in $\mathrm{Al}-10 \mathrm{wtpctNi}$ alloy solidified from $1023 \mathrm{~K}\left(750{ }^{\circ} \mathrm{C}\right)(\mathrm{melting}$ state) at a cooling rate of $18 \mathrm{~K} / \mathrm{min}$ under various magnetic fields: $(a) 0 \mathrm{~T}$; (b) $0.8 \mathrm{~T}$; (c) $0.9 \mathrm{~T}$; (d) $1.0 \mathrm{~T}$; (e) $1.5 \mathrm{~T}$; $(f) 12 \mathrm{~T}$. 

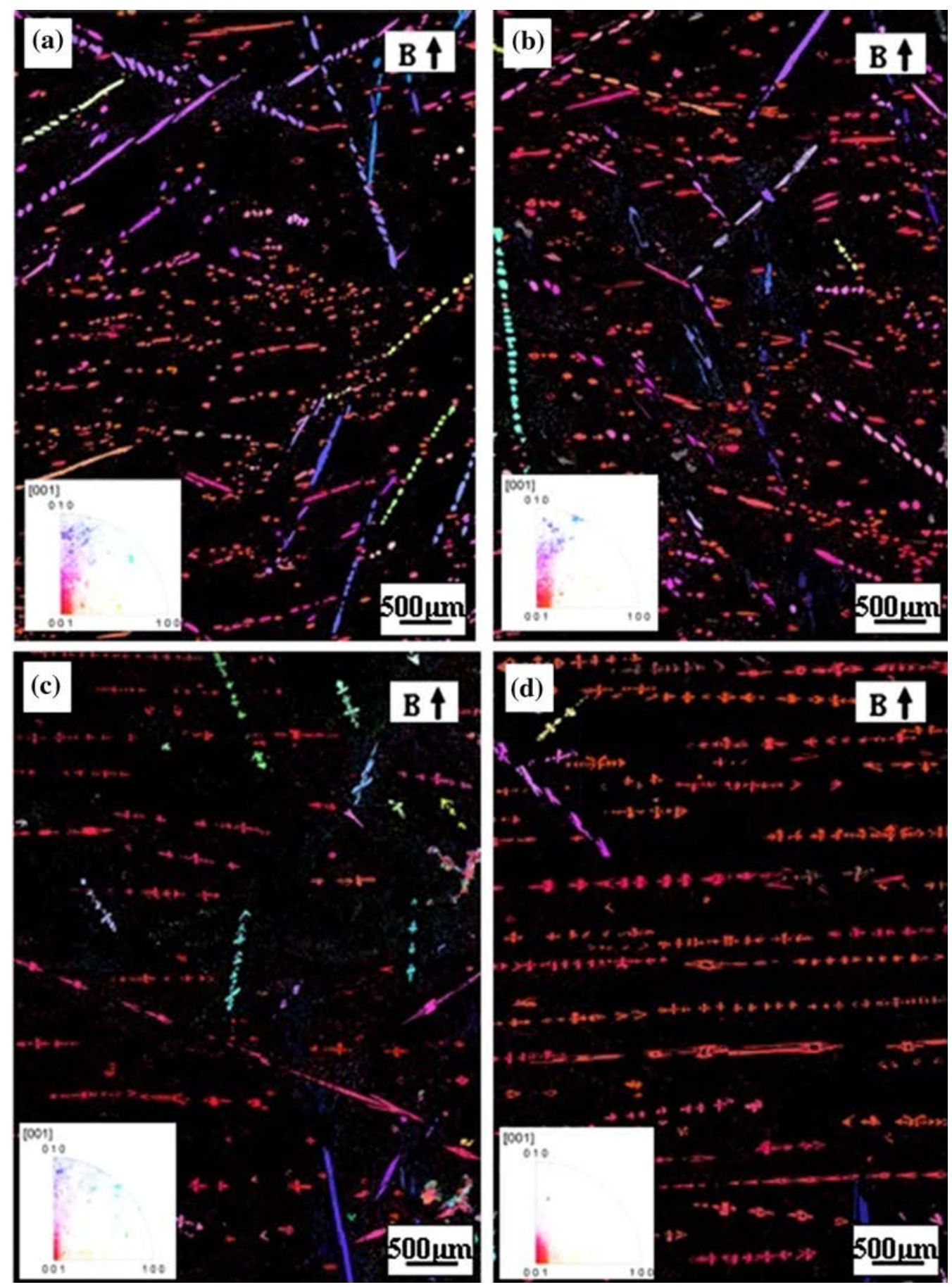

Fig. 3-EBSD maps and the corresponding pole figures for the $\mathrm{Al}_{3} \mathrm{Ni}$ phases in $\mathrm{Al}-10 \mathrm{wtpctNi}$ alloy solidified from a certain temperature in the semi-melting state at a cooling rate of $18 \mathrm{~K} / \mathrm{min}$ under a $10 \mathrm{~T}$ magnetic field: $($ a $) 958 \mathrm{~K}\left(685^{\circ} \mathrm{C}\right) ;(b) 963 \mathrm{~K}\left(690{ }^{\circ} \mathrm{C}\right) ;(c) 973 \mathrm{~K}\left(700{ }^{\circ} \mathrm{C}\right) ;(d)$ $983 \mathrm{~K}\left(710^{\circ} \mathrm{C}\right)$.

shows the EBSD maps and the corresponding pole figures for the $\mathrm{Al}_{3} \mathrm{Ni}$ phases in the $\mathrm{Al}-10 \mathrm{wtpctNi}$ alloy solidified from different temperatures in the semi-melting state under a 10-T magnetic field. It can be observed that, with the increase in the solidification temperature, the alignment degree of the $\mathrm{Al}_{3} \mathrm{Ni}$ primary phase increased. Figure 4 shows the EBSD results for the structures in solidified Al-Ni alloys with different $\mathrm{Ni}$ contents under a 10-T magnetic field. The $\mathrm{Al}_{3} \mathrm{Ni}$ primary phases in the $\mathrm{Al}-10 \mathrm{wtpctNi}$ alloys were well aligned under the magnetic field. However, with the increase in the $\mathrm{Ni}$ content, the alignment of the $\mathrm{Al}_{3} \mathrm{Ni}$ primary phase became weak.

To quantify the alignment behavior of the $\mathrm{Al}_{3} \mathrm{Ni}$ primary phase under various conditions, an alignment degree was defined as $\Gamma=N_{0} / N$, where $N$ is total 

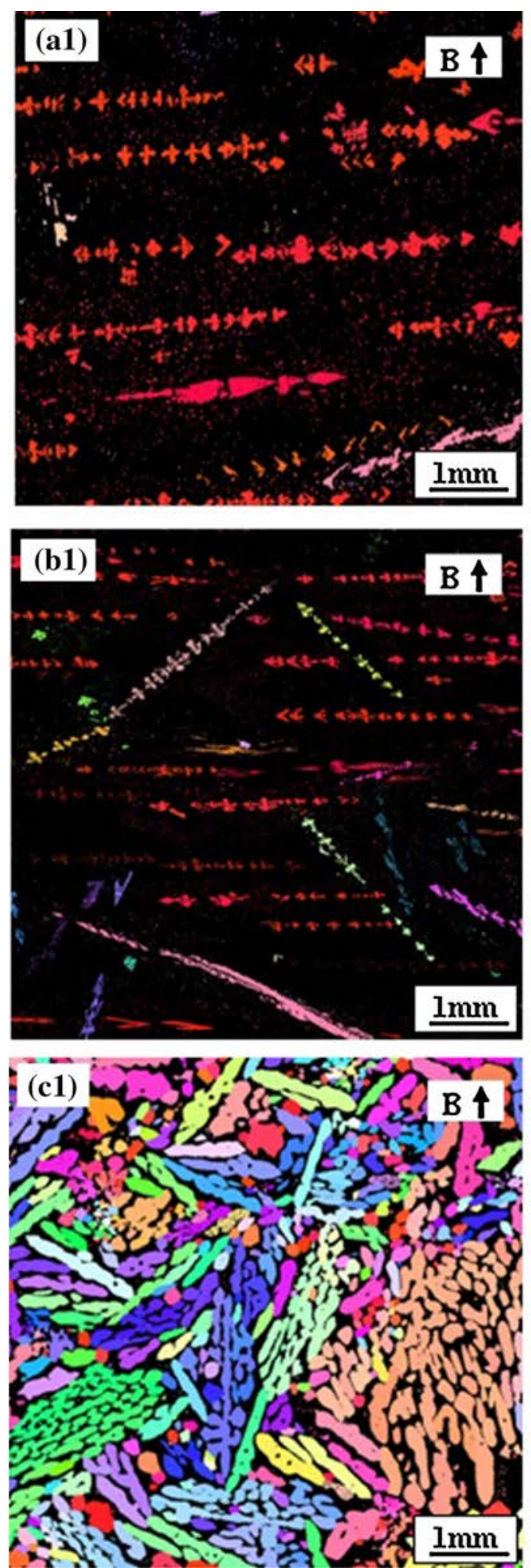

(a2)

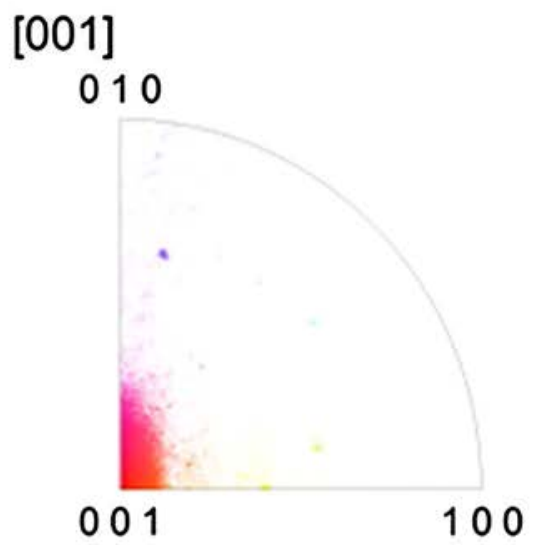

(b2)

[001]

010

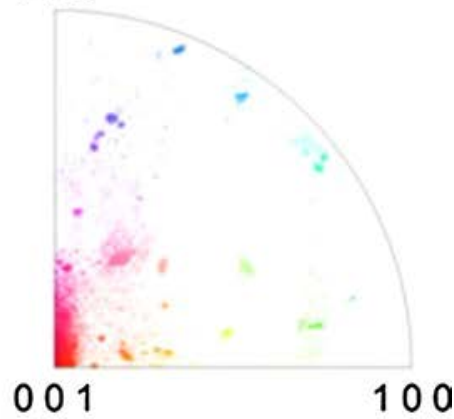

(c2)

[001]

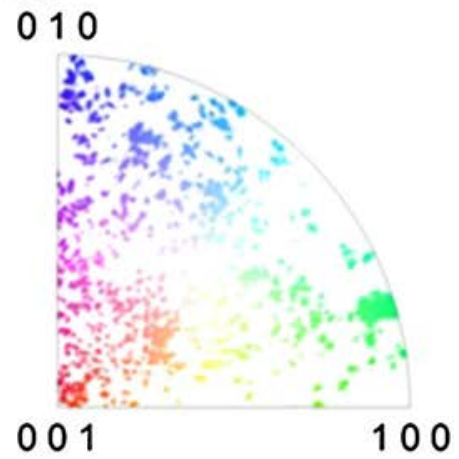

Fig. 4-EBSD maps and the corresponding pole figures for the $\mathrm{Al}_{3} \mathrm{Ni}$ phases in $\mathrm{Al}-\mathrm{Ni}$ alloys with various contents solidified from $1023 \mathrm{~K}$ $\left(750^{\circ} \mathrm{C}\right.$ ) at a cooling rate of $18 \mathrm{~K} / \mathrm{min}$ under a $10 \mathrm{~T}$ magnetic field: $(a)$ Al-10wtpctNi alloy; $(b)$ Al-15wtpctNi alloy; (c) Al-30wtpctNi alloy.

number of crystals per unit of section area and $N_{0}$ is the number of orientation crystals. In this context, a dendrite is considered an aligned dendrite when the angle between the $\langle 001\rangle$ crystal direction of the dendrite and the magnetic field direction is less than 2 deg. Figure 5(a) shows the dependence of the alignment degree $\Gamma$ on the magnetic field in the Al-10wtpctNi alloys solidified from $1023 \mathrm{~K}\left(750^{\circ} \mathrm{C}\right)$. It can be 


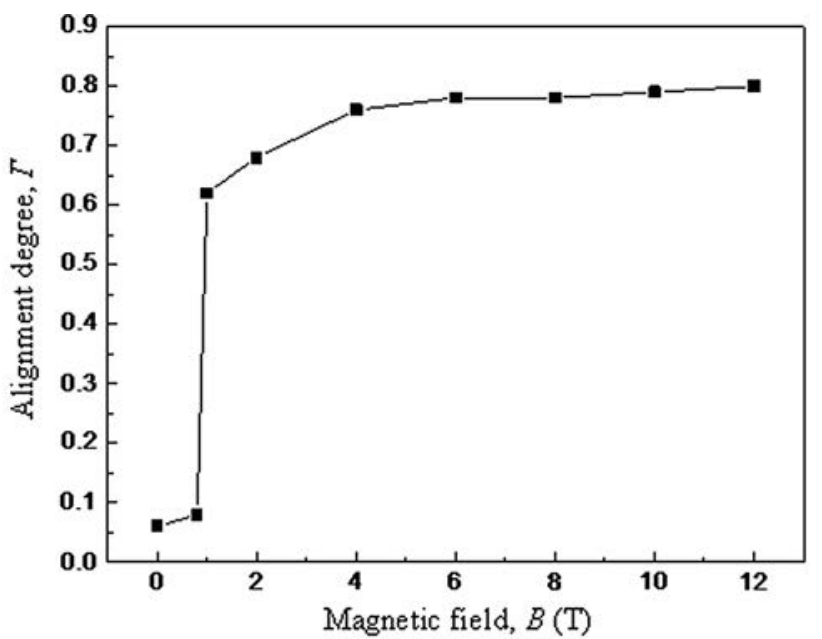

(a)

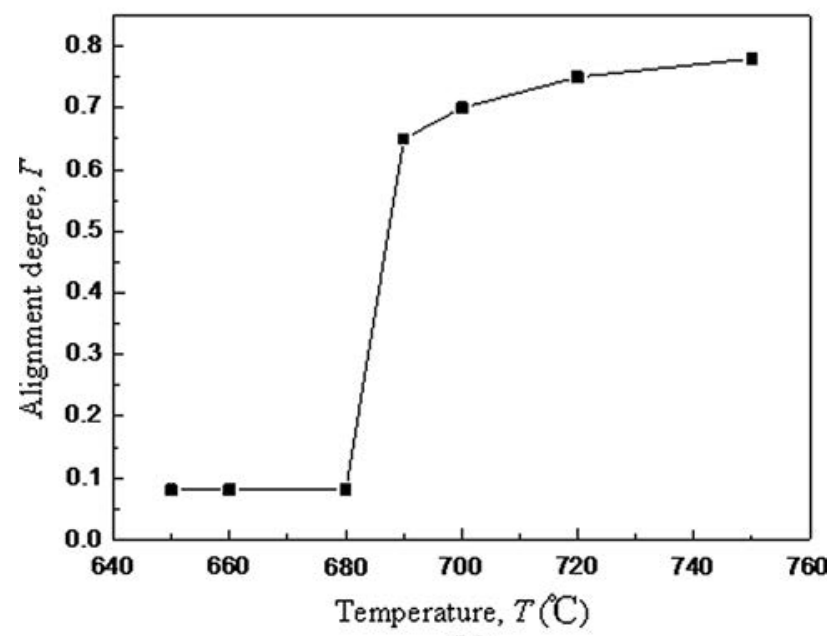

(b)

Fig. 5-Dependencies of the alignment degree $\Gamma$ of the primary $\mathrm{Al}_{3} \mathrm{Ni}$ phase on the solidification temperature $(T)$ and the magnetic field intensity $(B)$ in Al-10wtpctNi alloy solidified at a cooling rate of $18 \mathrm{~K} / \mathrm{min}$ : (a) $\Gamma$ as a function of the magnetic field intensity during the solidification from $1023 \mathrm{~K}\left(750^{\circ} \mathrm{C}\right) ;(b) \Gamma$ as a function of the solidification temperature under a $10 \mathrm{~T}$ magnetic field.

observed that when the magnetic field intensity exceeded a certain value, the alignment degree $\Gamma$ increased suddenly; the alignment was then enhanced as the magnetic field increased. Figure 5(b) shows the dependence of the alignment degree $(\Gamma)$ on the solidification temperature $(T)$ under a 10-T magnetic field. It can be observed that when the solidification temperature was below $953 \mathrm{~K}\left(680^{\circ} \mathrm{C}\right)$, the alignment degree was small. However, when the temperature exceeded $953 \mathrm{~K}$ $\left(680{ }^{\circ} \mathrm{C}\right)$, the alignment degree increased rapidly. The above-described results reveal that the alignment of the $\mathrm{Al}_{3} \mathrm{Ni}$ primary phase in the $\mathrm{Al}-\mathrm{Ni}$ alloys was mainly related to the following factors: the magnetic field intensity, the solidification temperature, and the $\mathrm{Ni}$ content.

To further study the formation mechanism of the alignment of the $\mathrm{Al}_{3} \mathrm{Ni}$ primary phase under a magnetic field, samples were quenched at various temperatures.
Figure 6 shows the EBSD results for the $\mathrm{Al}_{3} \mathrm{Ni}$ phases in the Al-10wtpct Ni alloy solidified from $1023 \mathrm{~K}\left(750^{\circ} \mathrm{C}\right)$ to a certain temperature at a cooling rate of $18 \mathrm{~K} / \mathrm{min}$; then, the samples were quenched at this temperature under a 10-T magnetic field. It can be observed that alignment occurred at the higher temperature and was enhanced throughout the solidification process under the magnetic field.

\section{B. Effect of a Magnetic Field on the $\mathrm{Al}_{3} \mathrm{Ni}$ Primary Phase During Directional Solidification}

Moreover, the effect of a magnetic field on the microstructures and crystalline orientation of the $\mathrm{Al}_{3} \mathrm{Ni}$ primary phase during directional solidification was also investigated. Figure 7 shows the EBSD maps and the corresponding pole figures for the $\mathrm{Al}_{3} \mathrm{Ni}$ phases in the directionally solidified Al-12wtpetNi alloys at various growth speeds with and without a 12-T magnetic field. The $\mathrm{Al}_{3} \mathrm{Ni}$ primary phases were aligned with the $\langle 010\rangle$ crystal direction along the solidification direction in the case in which no magnetic field was applied. With an imposed magnetic field of 12-T, compared to the microstructures observed in the case in which no field was applied, the microstructures and the orientation of the $\mathrm{Al}_{3} \mathrm{Ni}$ primary phase were significantly altered. As a consequence, the $\mathrm{Al}_{3} \mathrm{Ni}$ primary phase formed a regular layer-like structure, and the $\langle 001\rangle$ crystal direction was oriented along the solidification direction (i.e., the magnetic field direction). It can be observed that with the increase in the growth speed, the size of the $\mathrm{Al}_{3} \mathrm{Ni}$ primary phase and the layer spacing decreased. Figure 8 shows the EBSD maps and the corresponding pole figures for the $\mathrm{Al}_{3} \mathrm{Ni}$ phases in directionally solidified Al-12wtpctNi alloys grown at $50 \mu \mathrm{m} / \mathrm{s}$ under various magnetic field intensities. With an imposed field of 2-T, the aligned structure began to deviate from the solidification direction. When the magnetic field intensity exceeded $6 \mathrm{~T}$, the longer axis of the $\mathrm{Al}_{3} \mathrm{Ni}$ phase (i.e., the $\langle 010\rangle$ crystal direction) became oriented perpendicular to the solidification direction and ultimately formed a layer-like structure. The evolution of the structural transformation process with the increase in the magnetic field intensity clearly indicates that the preferred growth direction (i.e., the $\langle 010\rangle$ crystal direction) of the $\mathrm{Al}_{3} \mathrm{Ni}$ crystal gradually deviated from the solidification direction and formed planes perpendicular to the solidification direction (i.e., the magnetic field direction). Figures 9(a) and (b) shows the dependencies of the alignment degree $(\Gamma)$ on the growth speed $(R)$ and the magnetic field intensity $(B)$ for the Al-12wtpct Ni alloy, respectively. It can be observed that the alignment degree $(\Gamma)$ increased with the increase in the magnetic field $(B)$ and the decrease in the growth speed $(R)$.

\section{Effect of a Magnetic Field on the $\mathrm{Al}_{-} \mathrm{Al}_{3} \mathrm{Ni}$ Eutectic}

As is known, the crystallographic orientation relationship of the $\mathrm{Al}-\mathrm{Al}_{3} \mathrm{Ni}$ eutectic is a popular research topic. ${ }^{[2-24]}$ Hitherto, there remain ambiguities regarding the orientation of the $\mathrm{Al}-\mathrm{Al}_{3} \mathrm{Ni}$ eutectic, even in the case in which no magnetic field is applied. Therefore, it is 

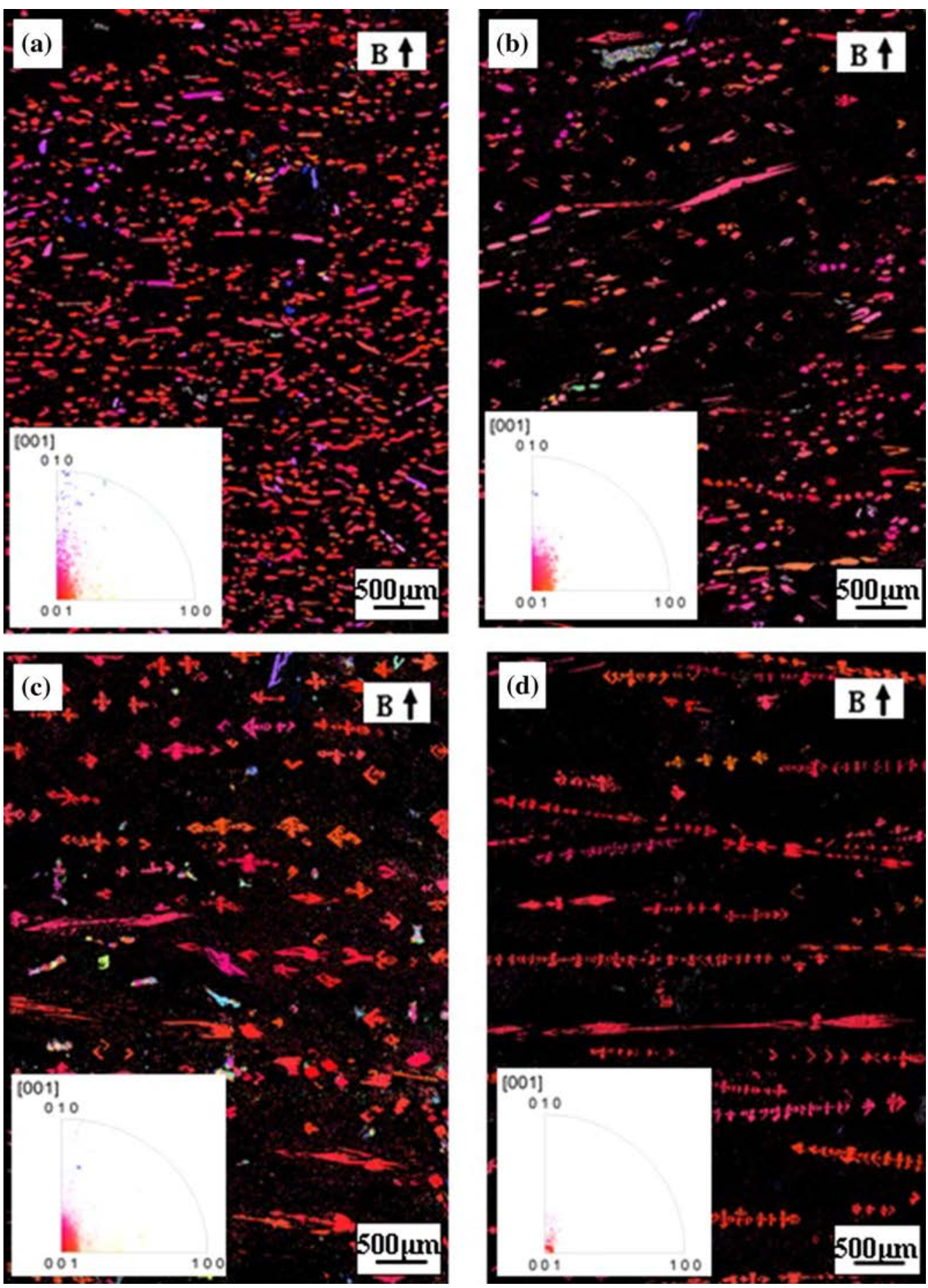

Fig. 6-EBSD maps and the corresponding pole figures for the $\mathrm{Al}_{3} \mathrm{Ni}$ phases in $\mathrm{Al}-10 \mathrm{wtpct} \mathrm{Ni}$ alloy solidified from $1023 \mathrm{~K}\left(750{ }^{\circ} \mathrm{C}\right)$ to a certain temperature at a cooling rate of $18 \mathrm{~K} / \mathrm{min}$ and then quenched under a $10 \mathrm{~T}$ magnetic field: $(a) 983 \mathrm{~K}\left(710{ }^{\circ} \mathrm{C}\right) ;(b) 973 \mathrm{~K}\left(700{ }^{\circ} \mathrm{C}\right) ;(c) 953 \mathrm{~K}$ $\left(680^{\circ} \mathrm{C}\right) ;(d) 913 \mathrm{~K}\left(640{ }^{\circ} \mathrm{C}\right)$.

necessary and valuable to deepen the understanding of the orientation relationship of the $\mathrm{Al}-\mathrm{Al}_{3} \mathrm{Ni}$ eutectic. In

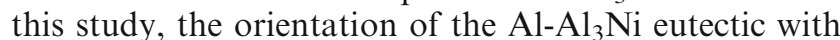
and without a magnetic field was studied in detail using EBSD technology. To determine the crystallographic orientation relationship between the $\mathrm{Al}$ and $\mathrm{Al}_{3} \mathrm{Ni}$ phases, the overlap between the pole figures of the
$\mathrm{Al}_{3} \mathrm{Ni}$ and $\mathrm{Al}$ phases was investigated. Based on this information, it is not difficult to understand that if the pole points in the pole figures overlap between the two eutectic phases, the crystal directions or planes in the two phases are parallel. Thus, the preferred orientation relationship in the eutectic may be determined. Figures 10 and 11 show the EBSD analysis for the 

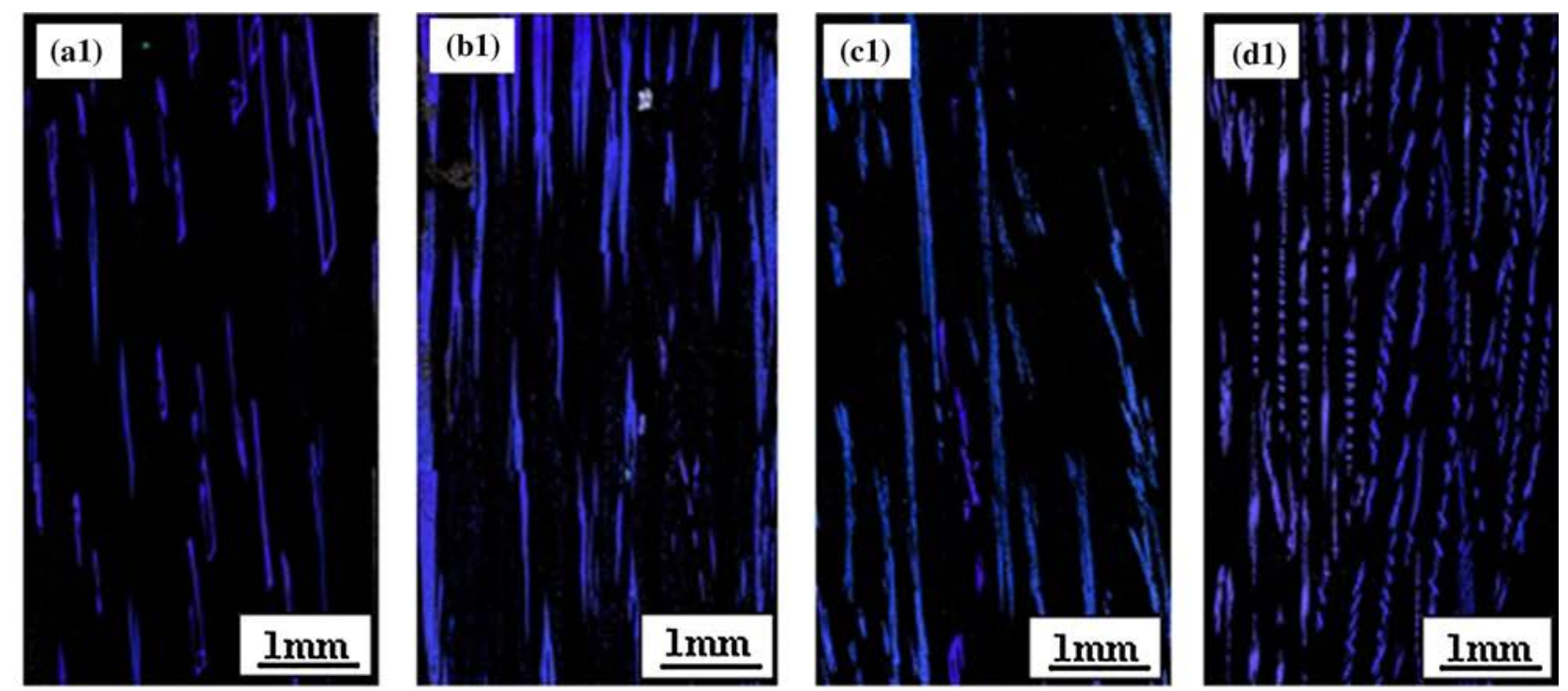

[001]

[001]

[001]

[001]

010

010

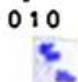

F

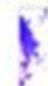

001

100

001

100

001

100

001

100
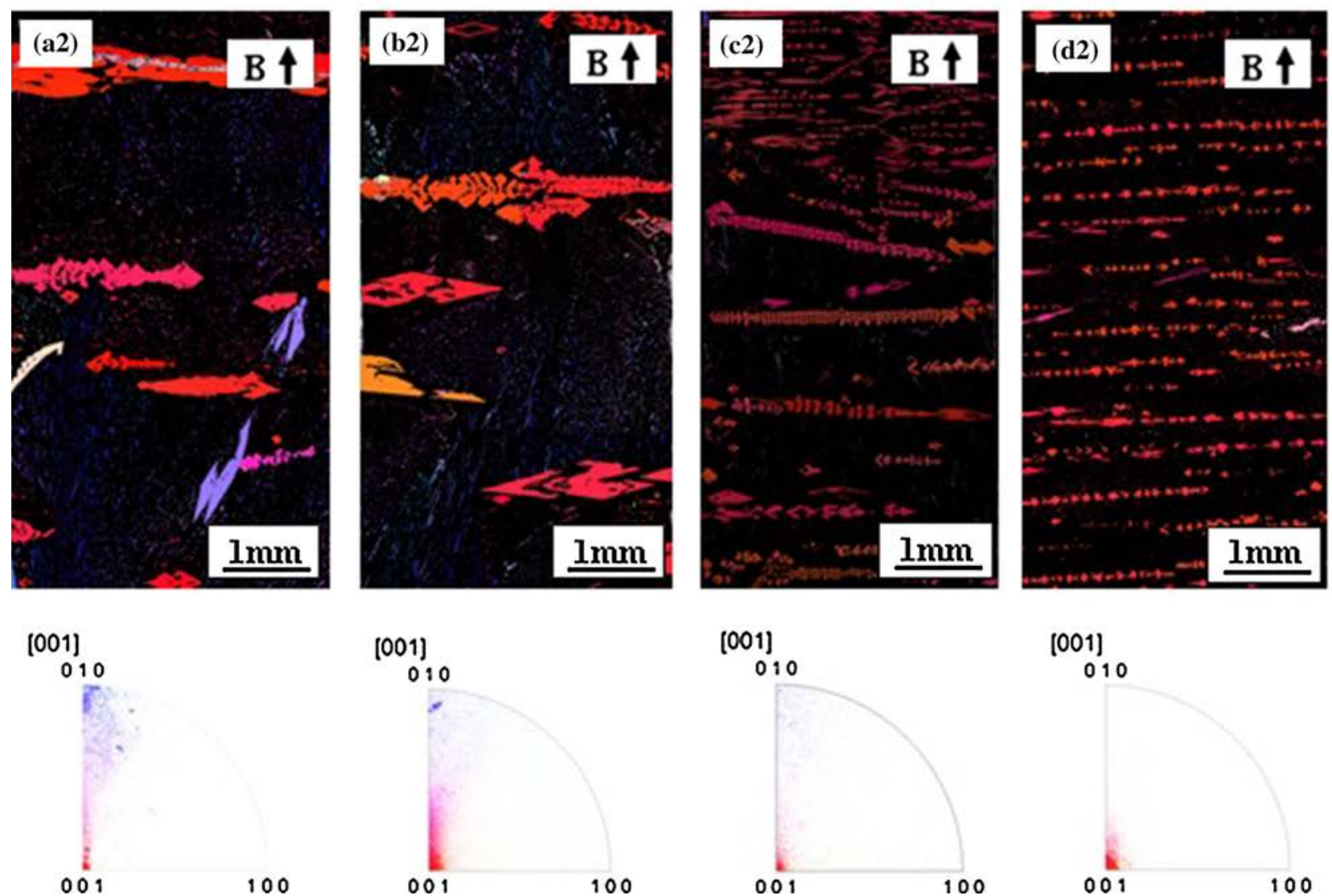

[001]

010

Fig. 7-EBSD maps and the corresponding pole figures for the $\mathrm{Al}_{3} \mathrm{Ni}$ phases in the longitudinal structures in directionally solidified $\mathrm{Al}-12 \mathrm{wt}-$ pctNi alloys at various growth speeds with and without a $12 \mathrm{~T}$ magnetic field: $(a) 5 \mu \mathrm{m} / \mathrm{s} ;(b) 10 \mu \mathrm{m} / \mathrm{s} ;(c) 50 \mu \mathrm{m} / \mathrm{s} ;(d) 100 \mu \mathrm{m} / \mathrm{s}$. 

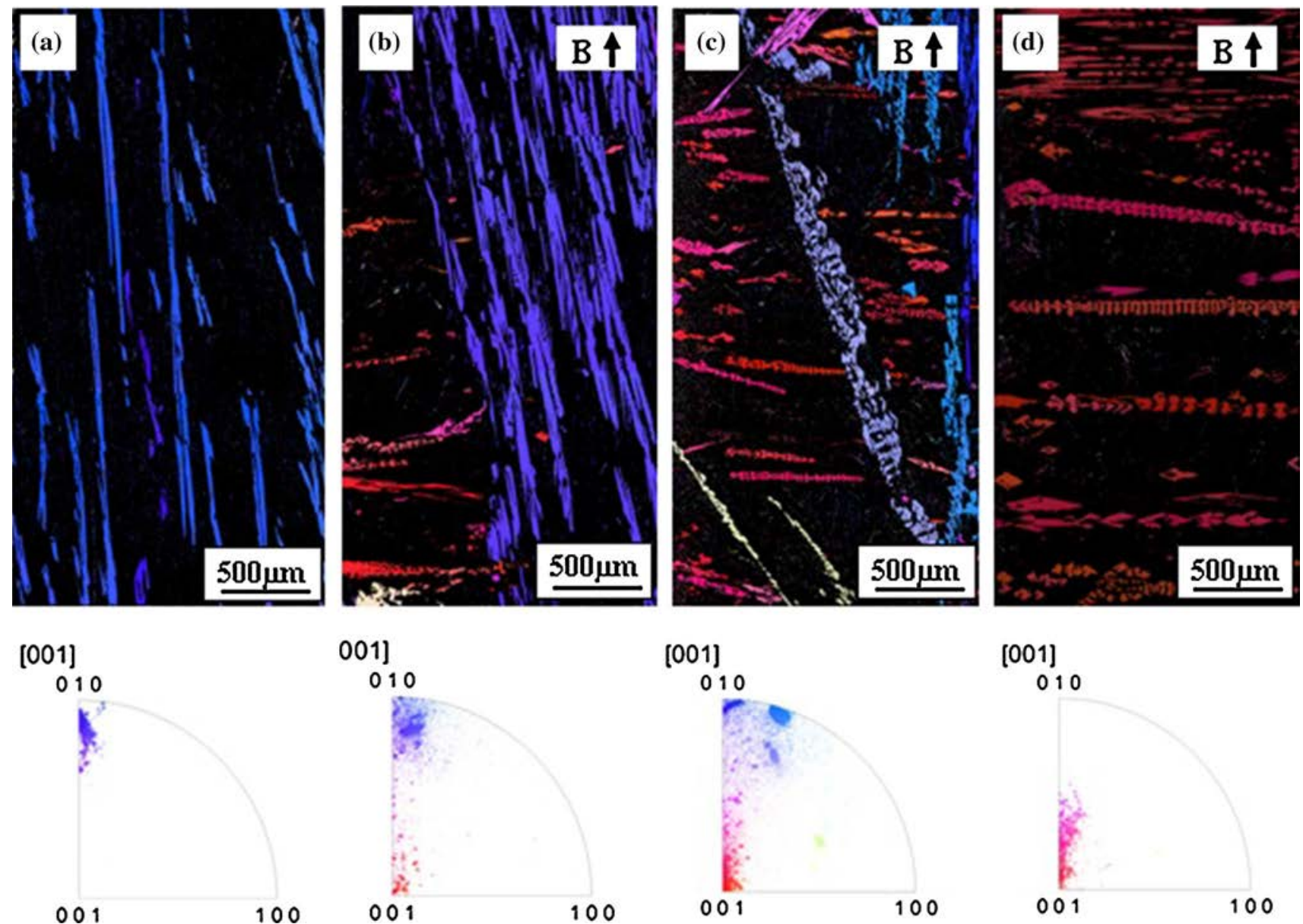

001]

010

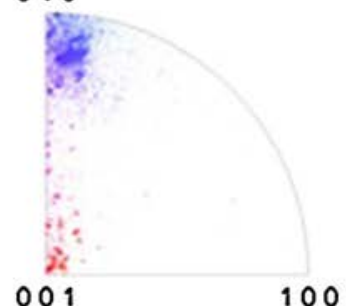

[001]

010

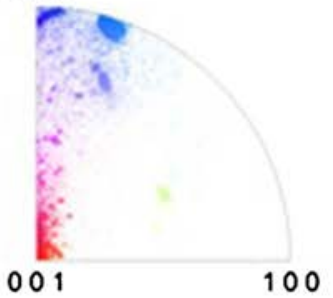

[001]

010

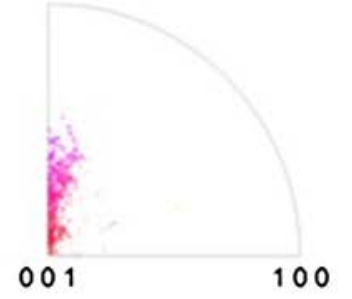

Fig. 8-EBSD maps and the corresponding pole figures for the $\mathrm{Al}_{3} \mathrm{Ni}$ phases in the longitudinal structures in directionally solidified $\mathrm{Al}-12 \mathrm{wt}-$ pctNi alloys at a growth speed of $50 \mu \mathrm{m} / \mathrm{s}$ under various magnetic fields: $(a) 0 \mathrm{~T} ;(b) 4 \mathrm{~T} ;(c) 6 \mathrm{~T} ;(d) 12 \mathrm{~T}$.

structures in directionally solidified Al-Ni eutectic and hypereutectic alloys, respectively. In the case in which no magnetic field was applied, both $\mathrm{Al}_{3} \mathrm{Ni}$ eutectic fibers and $\mathrm{Al}_{3} \mathrm{Ni}$ primary dendrites were aligned with the $\langle 010\rangle$ crystal direction along the solidification direction (see Figures 10(c) and 11(c)). By overlapping the pole figures of the $\mathrm{Al}_{3} \mathrm{Ni}$ and $\mathrm{Al}$ phases in the $\mathrm{Al}-\mathrm{Al}{ }_{3} \mathrm{Ni}$ eutectic (Figures 11(e) and (f)), the crystallographic orientation relationship in the $\mathrm{Al}-\mathrm{Al}_{3} \mathrm{Ni}$ eutectic in Al-Ni eutectic alloy was determined to be as follows:

$$
\langle 011\rangle \mathrm{Al} / /\langle 010\rangle \mathrm{Al}_{3} \mathrm{Ni} ; \quad \text { (011) } \mathrm{Al} / /(103) \mathrm{Al}_{3} \mathrm{Ni}
$$

The crystallographic orientation relationship in the $\mathrm{Al}-\mathrm{Al}_{3} \mathrm{Ni}$ eutectic in the $\mathrm{Al}-\mathrm{Ni}$ hypereutectic alloy was determined to be as follows:

$$
\begin{array}{ll}
\langle 011\rangle \mathrm{Al} / /\langle 010\rangle \mathrm{Al}_{3} \mathrm{Ni} ; & \text { (011) } \mathrm{Al} / /(103) \mathrm{Al}_{3} \mathrm{Ni} \\
\langle 001\rangle \mathrm{Al} / /\langle 010\rangle \mathrm{Al}_{3} \mathrm{Ni} ; & \text { (011) } \mathrm{Al} / /(103) \mathrm{Al}_{3} \mathrm{Ni}
\end{array}
$$

This preferred orientation relationship is consistent with the one reported in References 20,21. Figure 12 shows the EBSD results for the structures in the directionally solidified $\mathrm{Al}-\mathrm{Ni}$ eutectic alloy grown at $2 \mu \mathrm{m} / \mathrm{s}$ under a 12-T magnetic field. The $\mathrm{Al}_{3} \mathrm{Ni}$ eutectic fibers aligned with the $\langle 010\rangle$ crystal direction along the solidification direction. A small amount of the $\mathrm{Al}_{3} \mathrm{Ni}$ primary phases appeared and aligned with the $\langle 001\rangle$ crystal direction along the solidification direction. The appearance of the $\mathrm{Al}_{3} \mathrm{Ni}$ phases that were aligned with the $\langle 001\rangle$ crystal direction along the solidification direction should be attributed to the formation of the banded structure in the eutectic under a strong magnetic field. ${ }^{[25]}$ By overlapping the pole figures of the $\mathrm{Al}_{3} \mathrm{Ni}$ and Al phases in the eutectic (see Figure 11(f)), the crystallographic orientation relationship in the $\mathrm{Al}-\mathrm{Al}_{3} \mathrm{Ni}$ eutectic in the Al-Ni eutectic alloy was determined to be as follows:

$$
\langle 210\rangle \mathrm{Al} / /\langle 010\rangle \mathrm{Al}_{3} \mathrm{Ni} ; \quad(001) \mathrm{Al} / /(102) \mathrm{Al}_{3} \mathrm{Ni}
$$

The above-described results demonstrated that when the magnetic field was applied, the preferred growth direction of the $\mathrm{Al}_{3} \mathrm{Ni}$ eutectic fiber in the eutectic alloys was not appreciably affected (see Figure 12(d)). However, the orientation relationship was modified under the magnetic field. Figure 13 shows the EBSD maps and the corresponding pole figures for the structures in the directionally solidified Al-12wtpctNi hypereutectic alloys under a 12-T magnetic field. It can be observed that with the application of the magnetic field, along 


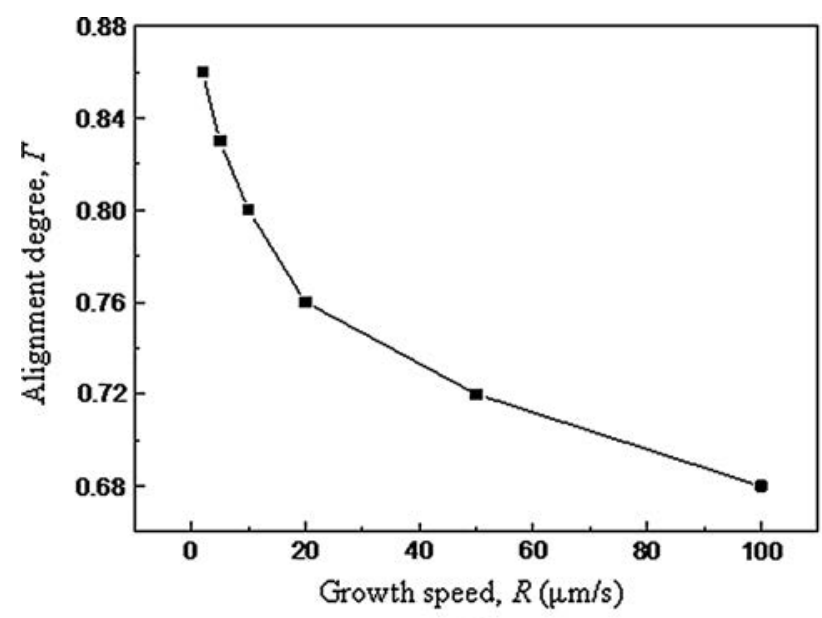

(a)

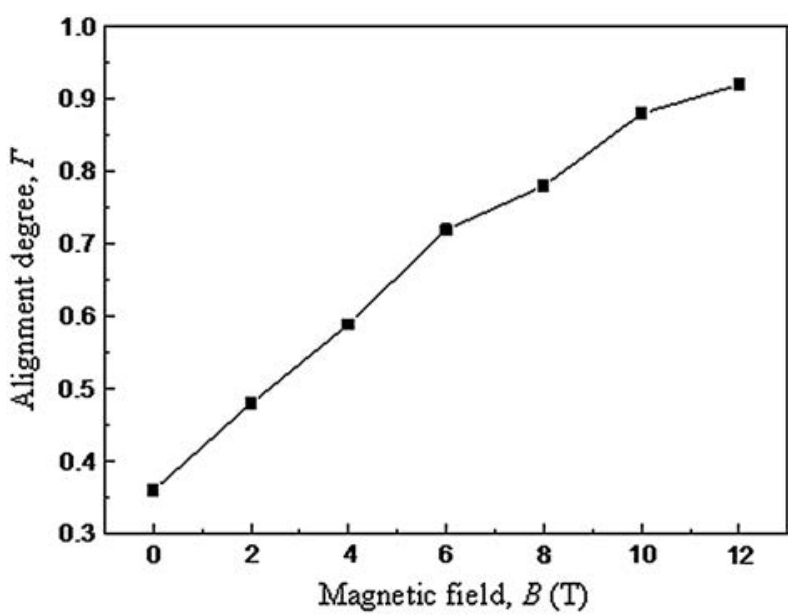

(b)

Fig. 9-Dependencies of the alignment degree $\Gamma$ of the primary $\mathrm{Al}_{3} \mathrm{Ni}$ phase in $\mathrm{Al}-12 \mathrm{wtpctNi}$ alloys on the growth speed $(R)$ and the magnetic field intensity $(B):(a) \Gamma$ as a function of the growth speed $(R)$ under a $6 \mathrm{~T}$ magnetic field; $(b) \Gamma$ as a function of the magnetic field intensity $(B)$ at a growth speed of $50 \mu \mathrm{m} / \mathrm{s}$.

with the alignment of the $\mathrm{Al}_{3} \mathrm{Ni}$ primary phases, the $\mathrm{Al}_{3} \mathrm{Ni}$ eutectic fiber (i.e., $\langle 010\rangle$ crystal direction) deflected from the solidification direction (see Figures 13(a) and (d)). Furthermore, by overlapping the pole figures of the $\mathrm{Al}_{3} \mathrm{Ni}$ and $\mathrm{Al}$ phases (see Figures 13(c) and (f)), the crystallographic orientation relationship in the $\mathrm{Al}-\mathrm{Al}_{3} \mathrm{Ni}$ eutectic in the Al-Ni hypereutectic alloy was determined to be as follows:

$$
\begin{array}{ll}
\langle 311\rangle \mathrm{Al} / /\langle 120\rangle \mathrm{Al}_{3} \mathrm{Ni} ; & (101) \mathrm{Al} / /(120) \mathrm{Al}_{3} \mathrm{Ni} \\
\langle 011\rangle \mathrm{Al} / /\langle 001\rangle \mathrm{Al}_{3} \mathrm{Ni} ; & (211) \mathrm{Al} / /(101) \mathrm{Al}_{3} \mathrm{Ni}
\end{array}
$$

The above-described results indicate that both the orientation of the preferred growth direction of the $\mathrm{Al}_{3} \mathrm{Ni}$ eutectic fiber and the crystallographic orientation relationship of the $\mathrm{Al}-\mathrm{Al}_{3} \mathrm{Ni}$ eutectic in the hypereutectic alloys were modified during directional solidification under the applied magnetic field. Furthermore, the effect of a strong magnetic field on the $\mathrm{Al}-\mathrm{Al}_{3} \mathrm{Ni}$ eutectic in the hypereutectic alloy during normal solidification was studied. Figure 14 shows the EBSD maps and the corresponding pole figures in the Al-12wtpct Ni alloy solidified from $1023 \mathrm{~K}\left(750^{\circ} \mathrm{C}\right)$ at a cooling rate of $1 \mathrm{~K} /$ min under a 12-T magnetic field. It can be observed that the orientation of the $\mathrm{Al}_{3} \mathrm{Ni}$ eutectic fiber was similar to that of the $\mathrm{Al}_{3} \mathrm{Ni}$ primary phase. This finding implies that the orientation of the $\mathrm{Al}_{3} \mathrm{Ni}$ primary phase was capable of affecting the growth of the $\mathrm{Al}_{3} \mathrm{Ni}$ eutectic fibers.

\section{DISCUSSION}

\section{A. Effect of a Magnetic Field on the $\mathrm{Al}_{3} \mathrm{Ni}$ Primary Phase During Normal Solidification}

The above-described experimental results indicate that the applied magnetic field aligned the $\mathrm{Al}_{3} \mathrm{Ni}$ primary phase with the $\langle 001\rangle$ crystal direction along the magnetic field direction. As is known, a crystal with magneto-crystalline anisotropy is magnetized under a magnetic field, and thus, a magnetic torque $M$ is induced. The magnetic torque $M$ can be expressed as follows: ${ }^{[26]}$

$$
M=|\Delta \chi| B^{2} V \sin 2 a / 2 \mu_{0},
$$

where $\Delta \chi=\chi_{\mathrm{c}}-\chi_{\mathrm{a}, \mathrm{b}}$ is the anisotropy in the volume magnetic susceptibility, $V$ is the primary crystal volume, $\mu_{0}$ is the vacuum permeability, and $\alpha$ is the angle between $B$ and the axis with the maximum $|\chi|$. Alignment will occur when the anisotropic energy is greater than the thermal energy, expressed as follows: ${ }^{[27]}$

$$
\Delta E=|\Delta \chi| B^{2} V / 2 \mu_{0}>k_{\mathrm{B}} T,
$$

where $k_{\mathrm{B}}$ is Boltzmann's constant and Tis the absolute temperature. From Eq. [1], it follows that a paramagnetic crystal in a homogeneous magnetic field will align itself with an easy magnetization axis along the magnetic field direction, whereas a diamagnetic crystal will align itself with the easy magnetization axis perpendicular to the magnetic field. The alignment of the $\mathrm{Al}_{3} \mathrm{Ni}$ phase under the magnetic field should be attributed to the rotating alignment caused by the magneto-crystalline anisotropy of the $\mathrm{Al}_{3} \mathrm{Ni}$ crystal. It has been proved that the $\mathrm{Al}_{3} \mathrm{Ni}$ phase is orthorhombic and paramagnetic. ${ }^{[28,29]}$ The above-described experimental results demonstrated that the $\langle 001\rangle$ and $\langle 010\rangle$ crystal directions of the $\mathrm{Al}_{3} \mathrm{Ni}$ crystal may be the easy magnetic axis and the preferred growth direction, respectively. Thus, along with the orientation of the $\langle 001\rangle$ crystal direction along the magnetic field (see Figure 15(a)), the longer axis of the dendrite (the $\langle 010\rangle$ crystal direction) is squared with the strength of the applied magnetic field. As a consequence, the plane of the $\mathrm{Al}_{3} \mathrm{Ni}$ phase will form as shown in Figures 15(b) through (d). In principle, the orienting action of the magnetic field must always affect a crystal with magnetic anisotropy in the case in which the anisotropic energy is greater than the thermal energy. However, due to the existence of viscous forces and the interaction of crystals with each other and with the walls of the crucible, the alignment may not occur. 


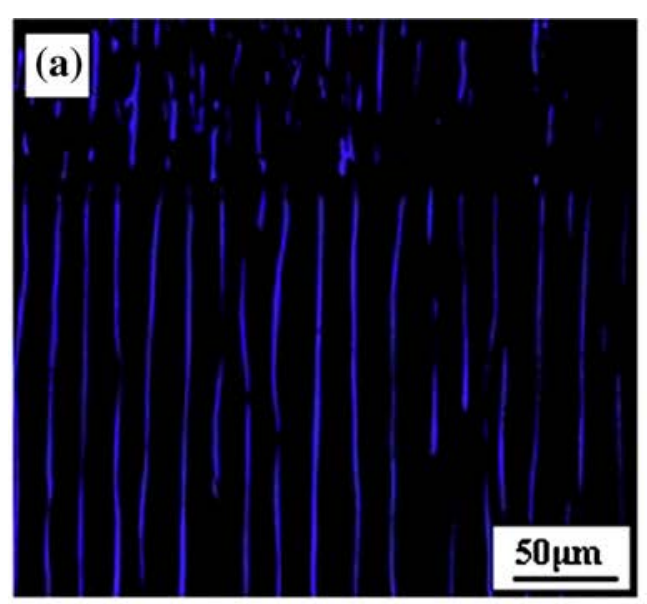

(c)

010

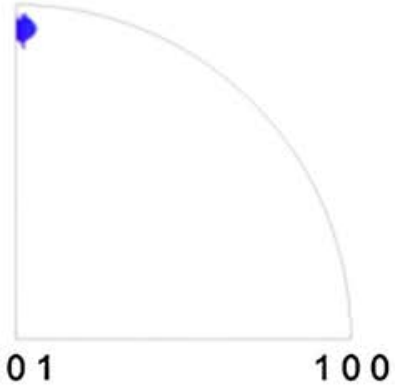

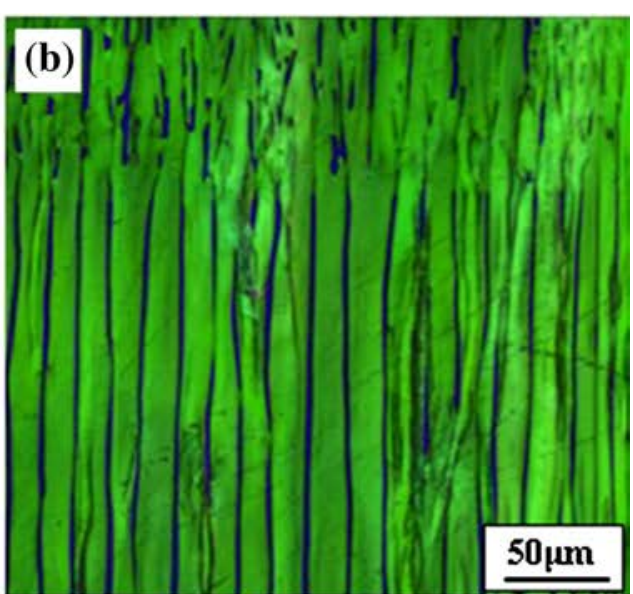

(d)

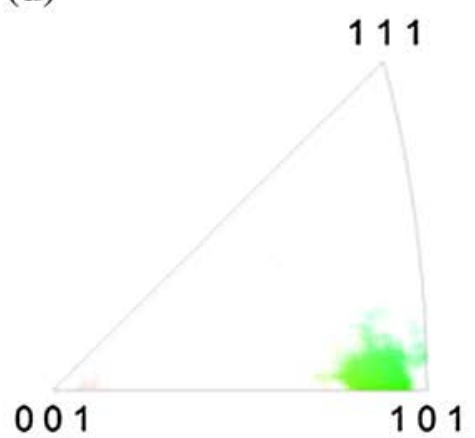

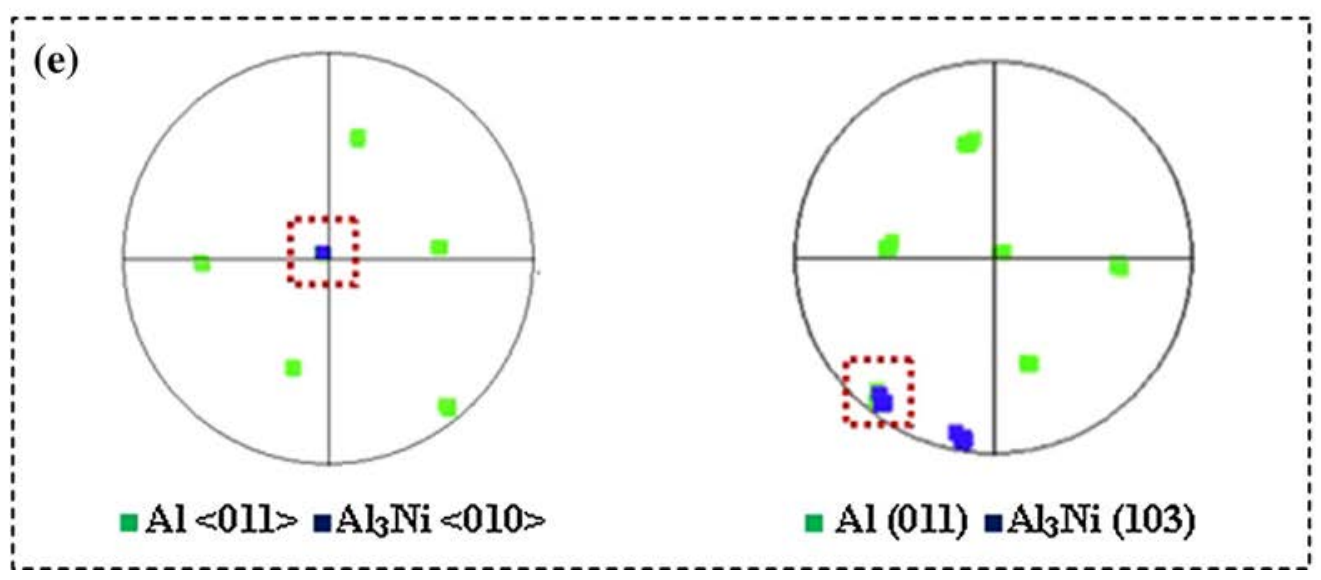

Fig. 10-EBSD maps and the corresponding pole figures for the structures near the liquid/solid interface in the directionally solidified Al-Ni eutectic alloy at $1 \mu \mathrm{m} / \mathrm{s}$ without a magnetic field: $(a)$ and $(c)$ EBSD maps and the corresponding pole figures for the $\alpha$-Al phases, respectively; $(b)$ and $(d)$ EBSD maps and the corresponding pole figures for the $\mathrm{Al}_{3} \mathrm{Ni}$ phases, respectively; (e) overlap between the $\mathrm{Al}\langle 011\rangle$ and $\mathrm{Al}{ }_{3} \mathrm{Ni}\langle 010\rangle$ pole figures and overlap between the $\mathrm{Al}(011)$ and the $\mathrm{Al}_{3} \mathrm{Ni}(103)$ pole figures.

The liquid viscosity induces a rotating torque $R$ that prevents rotation:

$$
R=r^{3} \eta v
$$

where $\eta$ is the viscosity, $r$ is the radius of the crystalline grains, and $v$ is the rotational speed. With the increase in the magnetic field intensity, the magnetic torque $M$ increases; therefore, the alignment factor increases with the increase in the magnetic field (see Figures 2 and 5(a)). Because the viscous forces decrease with the increase in the solidification temperature, the alignment factor increases with the increase in temperature (see Figures 3 and 5(b)). The above-mentioned results demonstrated that with the increase in the Ni content, the alignment degree decreases. This effect should be attributed to the increase in the viscous forces with the increase in the $\mathrm{Ni}$ content. At the same time, owing to 

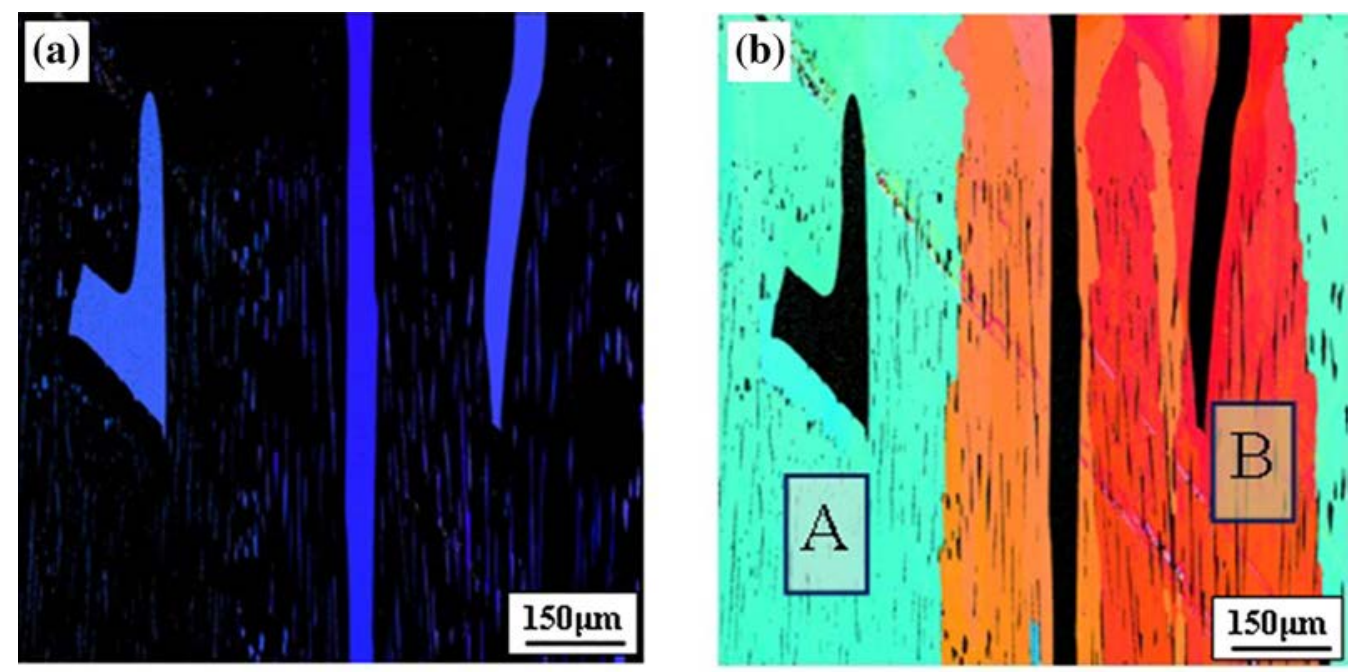

(c)

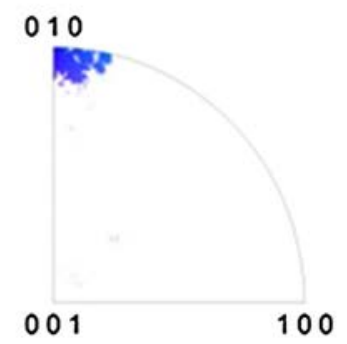

(d)

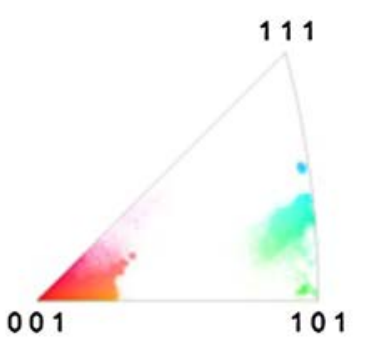

(e)

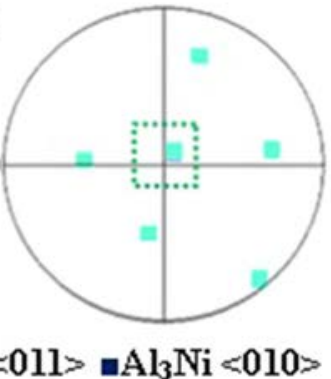

$=\mathrm{Al}<011>-\mathrm{Al}_{3} \mathrm{Ni}<010>$

(f)

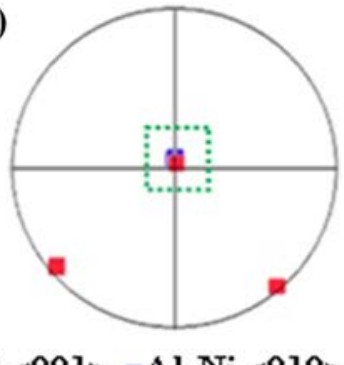

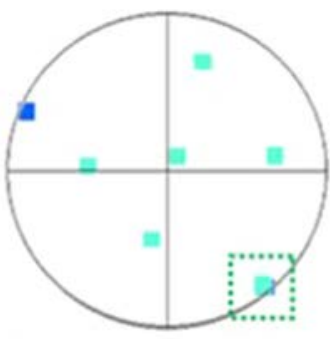

$\because \mathrm{Al}(011)=\mathrm{Al}{ }_{3} \mathrm{Ni}(103)$

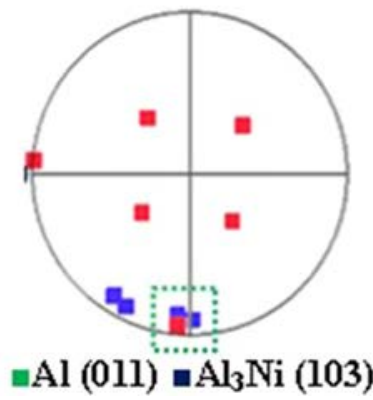

Fig. 11-EBSD maps and the corresponding pole figures for the structures near the liquid/solid interface in the directionally solidified Al-Ni eutectic alloy at $2 \mu \mathrm{m} / \mathrm{s}$ without a magnetic field: $(a)$ and (c) EBSD maps and the corresponding pole figures for the $\alpha$-Al phases, respectively; $(b)$ and $(d)$ EBSD maps and the corresponding pole figures for the $\mathrm{Al}_{3} \mathrm{Ni}$ phases, respectively; $\left(e\right.$ ) overlap between $\mathrm{Al}\langle 011\rangle$ and $\mathrm{Al}{ }_{3} \mathrm{Ni}\langle 010\rangle$ pole figures and overlap between $\mathrm{Al}(011)$ and $\mathrm{Al}_{3} \mathrm{Ni}(103)$ pole figures in $A$ region; $(f)$ overlap between $\mathrm{Al}\langle 001\rangle$ and $\mathrm{Al}_{3} \mathrm{Ni}\langle 010\rangle$ pole figures and overlap between the $\mathrm{Al}(011)$ - and $\mathrm{Al}_{3} \mathrm{Ni}$ (103)-pole figures in $B$ region.

the increase in the Ni composition, the phase crystallization speed will increase. Thus, the interaction between the phases will increase, and the formation of the regular aligned structure is hindered (see Figure 4).

\section{B. Effect of a Magnetic Field on the $\mathrm{Al}_{3} \mathrm{Ni}$ Primary Phase During Directional Solidification}

During directional solidification under a magnetic field, an anisotropic crystal will grow along the preferred growth direction; concurrently, the magnetic field will tend to rotate the easy axis of the crystal toward the magnetic field direction. Thus, when the easy axis of a crystal is the same as the preferred growth direction, an axial magnetic field enhances the growth along the solidification direction during the directional solidification process. However, if there exists an angle between the easy magnetization axis and the preferred growth direction, the preferred growth direction will deviate from the solidification direction during which the easy magnetization axis will rotate toward the magnetic field direction. In particular, when the easy magnetization axis of a crystal is perpendicular to its preferred growth direction, the axial magnetic field will cause the preferred growth direction to rotate 


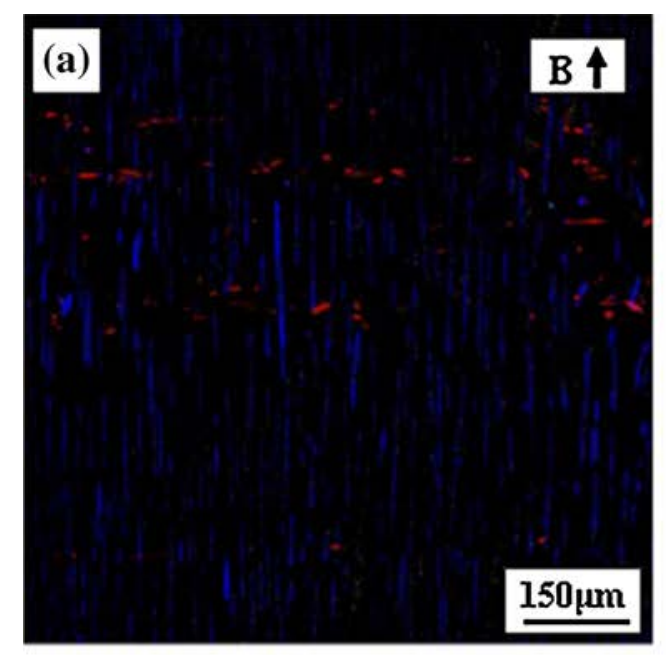

(c) 010
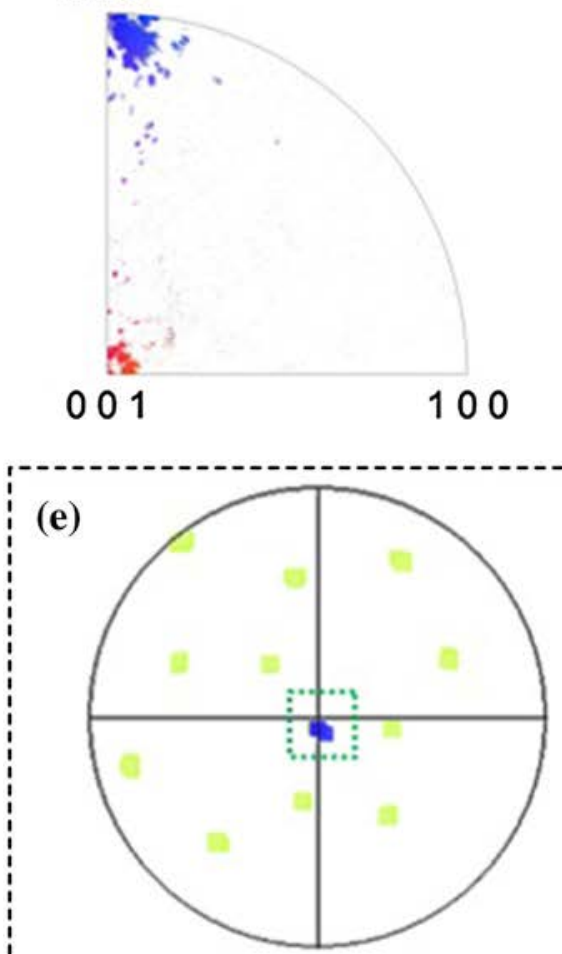

$=\mathrm{Al}<210>-\mathrm{Al}_{3} \mathrm{Ni}<010>$

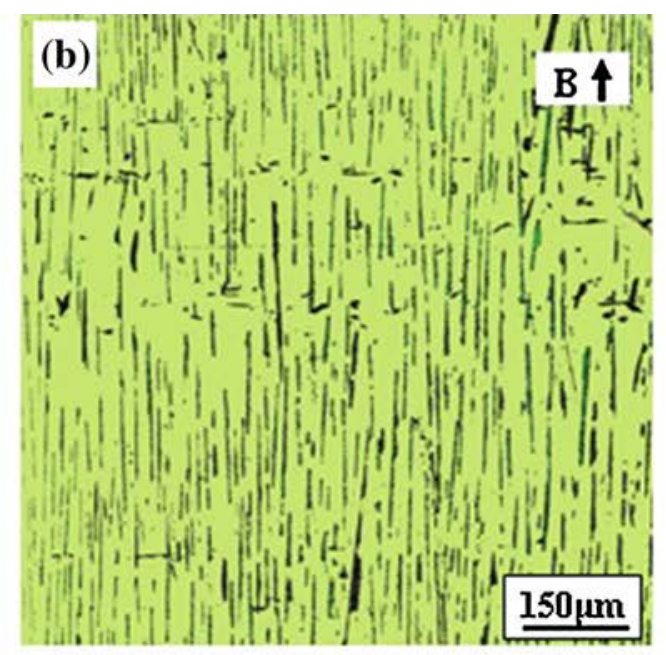

(d)

\section{1}

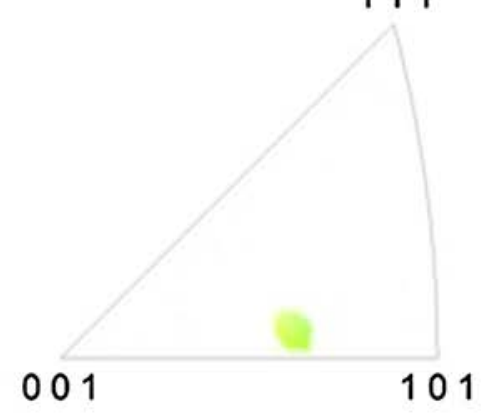

Fig. 12-EBSD maps and the corresponding pole figures for the structures in the directionally solidified Al-Ni eutectic alloy at $2 \mu \mathrm{m} / \mathrm{s}$ under a 12-T magnetic field: $(a)$ and $(c)$ EBSD maps and the corresponding pole figures for the $\alpha$-Al phases, respectively; $(b)$ and $(d)$ EBSD maps and the corresponding pole figures for the $\mathrm{Al}_{3} \mathrm{Ni}$ phases, respectively; $(e)$ overlap between the $\mathrm{Al}\langle 001\rangle$ and $\mathrm{Al}_{3} \mathrm{Ni}\langle 102\rangle$ pole figures and overlap between the $\mathrm{Al}(210)$ and $\mathrm{Al}_{3} \mathrm{Ni}(103)$ pole figures.

toward the plane perpendicular to the solidification direction. Consequently, a layer-like structure is formed. The orientation of the $\mathrm{Al}_{3} \mathrm{Ni}$ crystal examined in this study should behave in this manner. The $\langle 001\rangle$ and $\langle 010\rangle$ crystal directions of the $\mathrm{Al}_{3} \mathrm{Ni}$ crystal are the easy magnetization axis and the preferred growth direction, respectively; therefore, the $\langle 001\rangle$ crystal direction of the $\mathrm{Al}_{3} \mathrm{Ni}$ crystal tends to rotate toward the direction of an applied magnetic field.
Moreover, owing to the Seebeck effect, ${ }^{[30]}$ a thermoelectric magnetic force will be acting on the dendrites during directional solidification under a magnetic field, as shown in Figure 16(a). ${ }^{[31]}$ This force can be expressed as follows:

$$
F_{\mathrm{S}}=\frac{-\sigma_{\mathrm{L}} \sigma_{\mathrm{S}} f_{\mathrm{L}}}{\sigma_{\mathrm{L}} f_{\mathrm{L}}+\sigma_{\mathrm{S}} f_{\mathrm{S}}}\left(S_{\mathrm{S}}-S_{\mathrm{L}}\right) \mathrm{GB},
$$




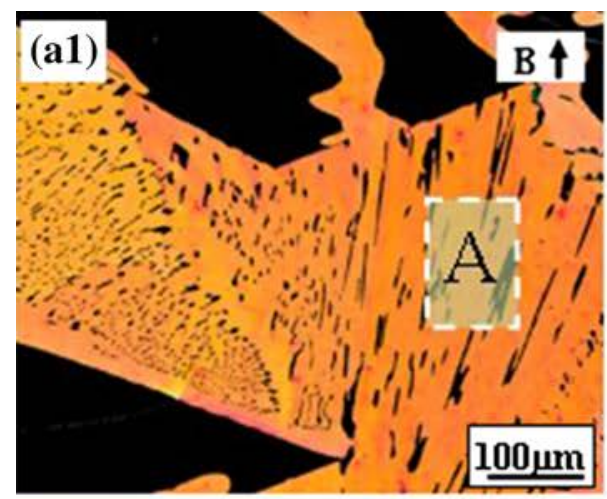

(b1)

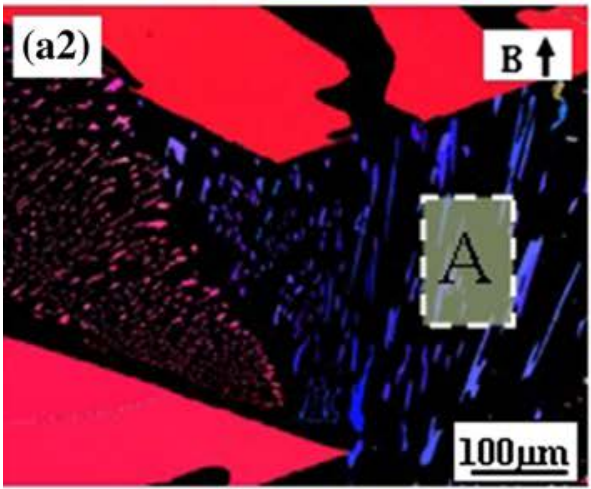

(b2)
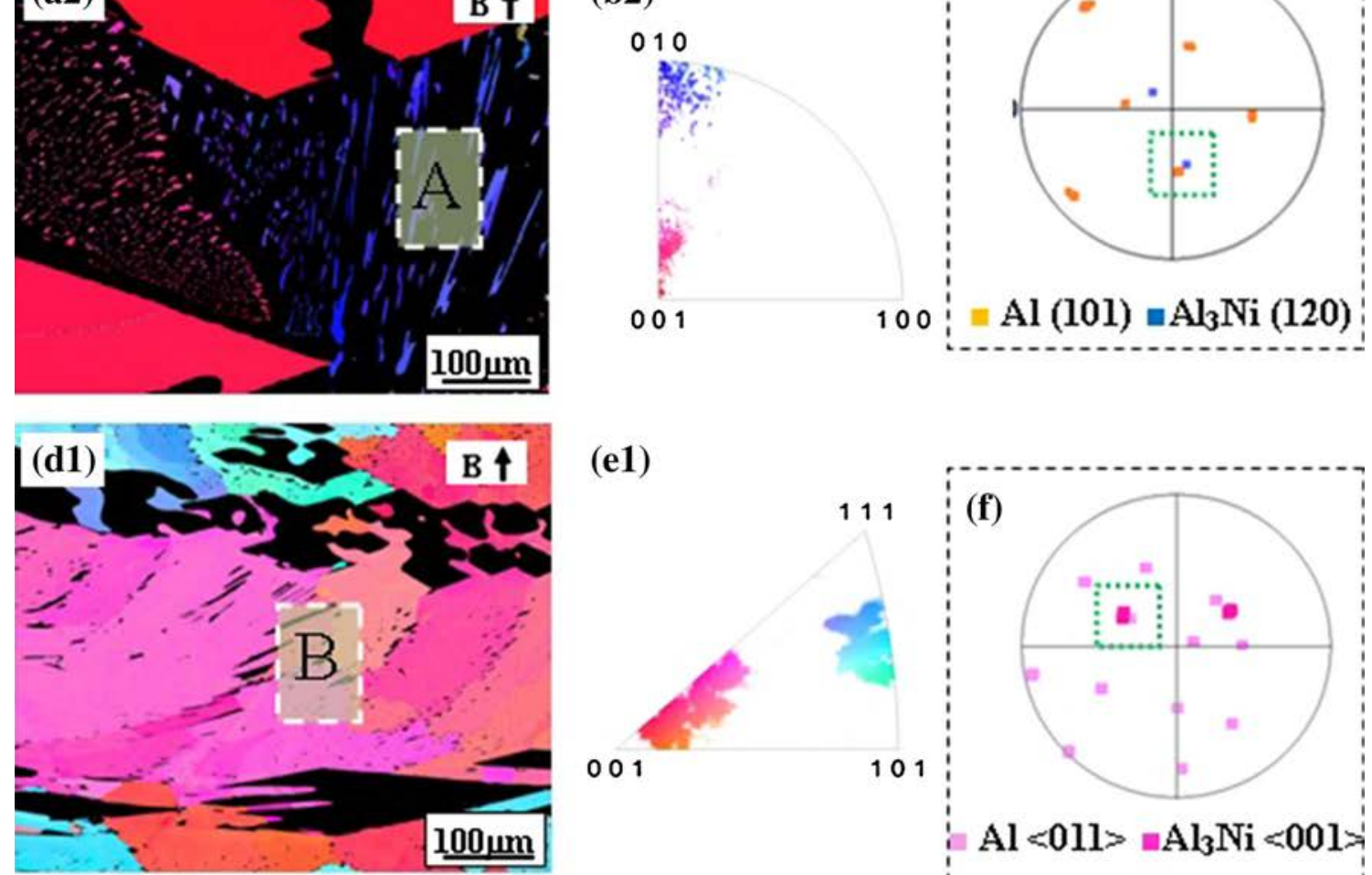

(e1)

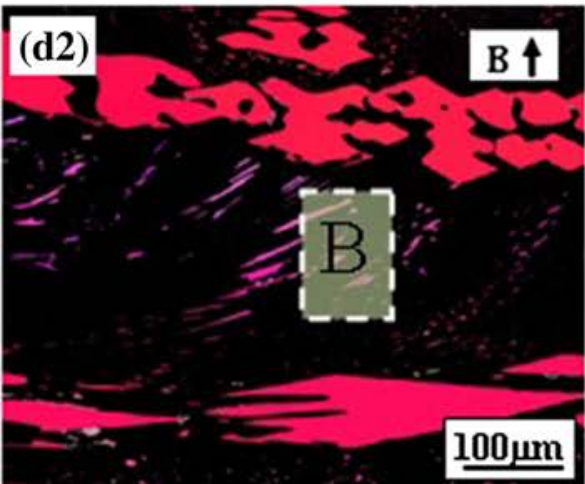

(e2)

010
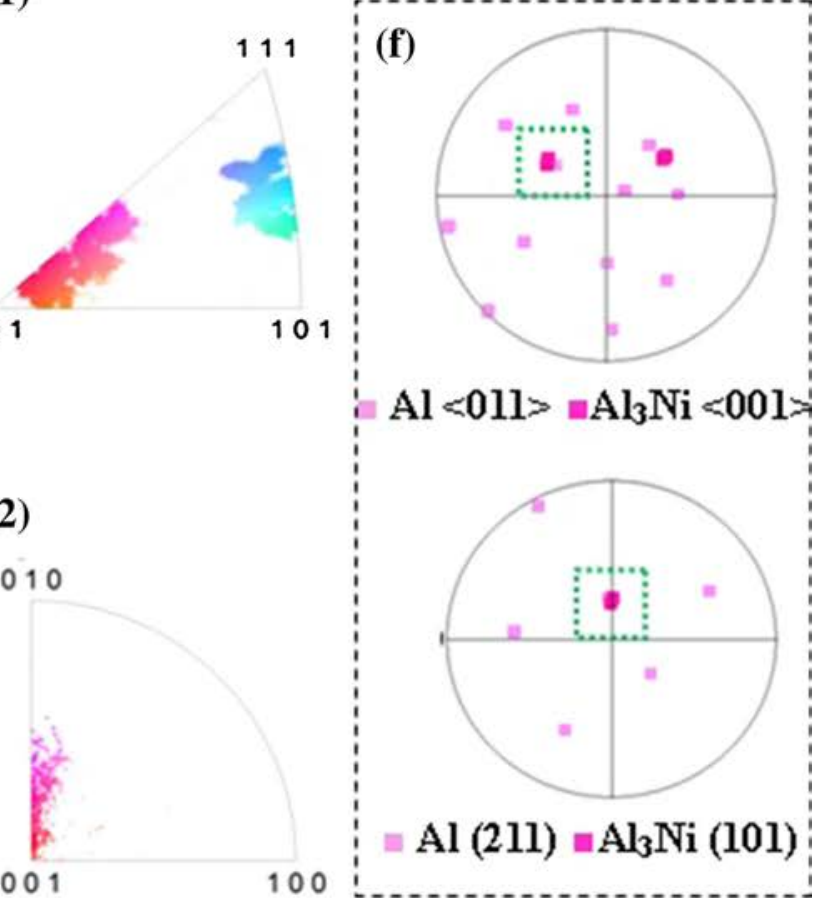

Fig. 13-EBSD maps and the corresponding pole figures for longitudinal structures in the directionally solidified Al-12wtpctNi alloys with a 12-T magnetic field: $(a)$ and (b) EBSD maps and the pole figures at $5 \mu \mathrm{m} / \mathrm{s}$, respectively; $(c)$ overlap between the $\mathrm{Al}\langle 311\rangle$ and the $\mathrm{Al}_{3} \mathrm{Ni}\langle 102\rangle$ pole figures and overlap between the $\mathrm{Al}(101)$ and the $\mathrm{Al}_{3} \mathrm{Ni}(120)$ pole figures for the structure in the $A$ region; $(d)$ and $(e)$ showing EBSD maps and the corresponding pole figures at $50 \mu \mathrm{m} / \mathrm{s}$, respectively; $(f)$ overlapping between the $\mathrm{Al}\langle 011\rangle$ and the $\mathrm{Al}_{3} \mathrm{Ni}\langle 001\rangle$ pole figures and overlap between the $\mathrm{Al}(211)$ and the $\mathrm{Al}_{3} \mathrm{Ni}(101)$ pole figures in the $B$ region. 


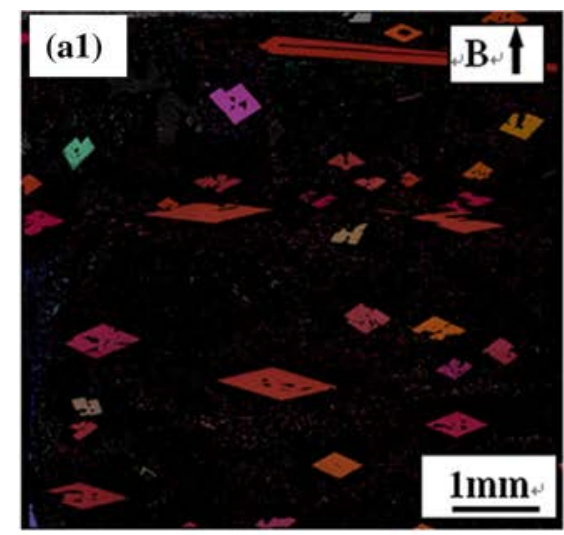

(a2)
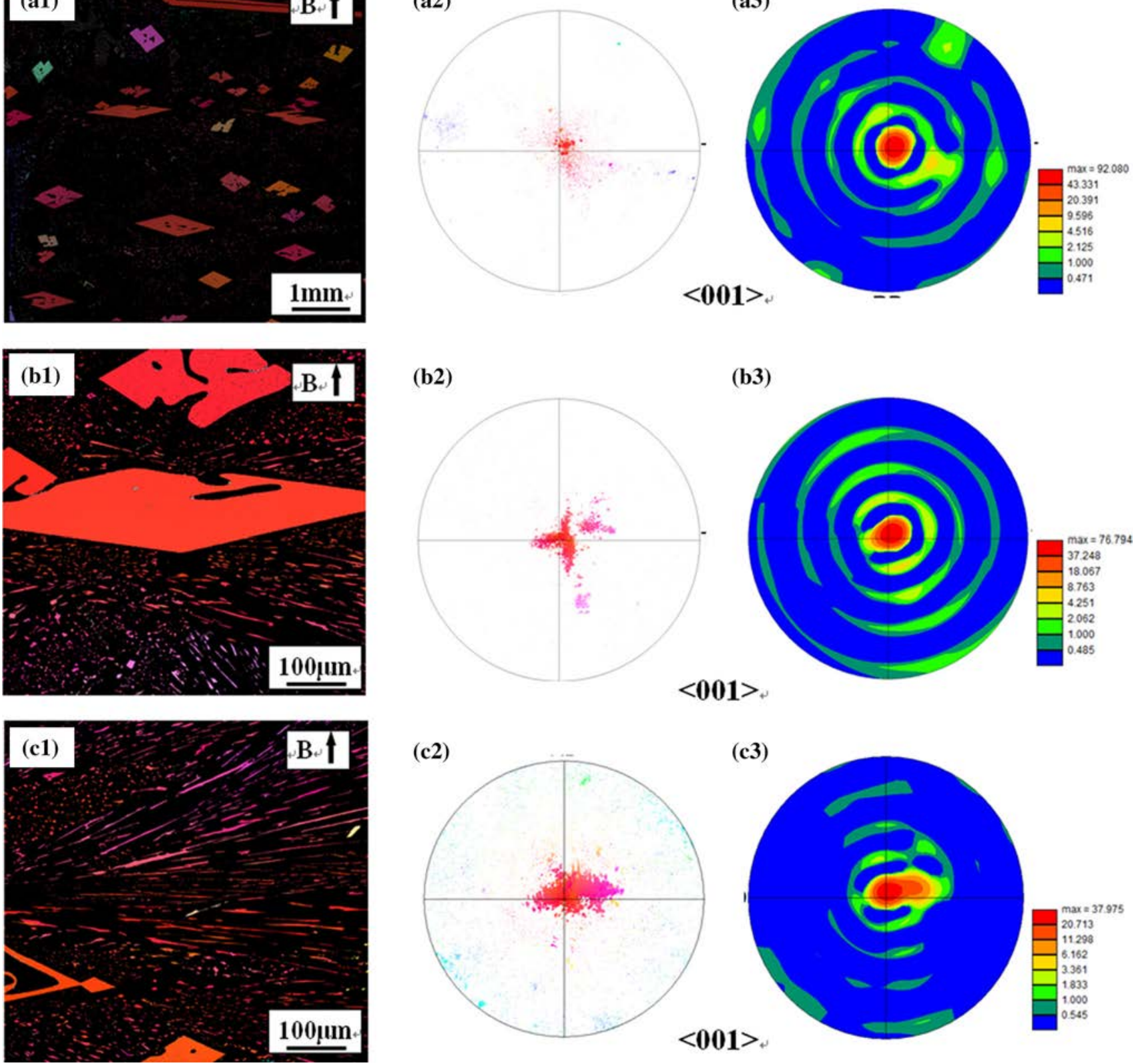

(b2)

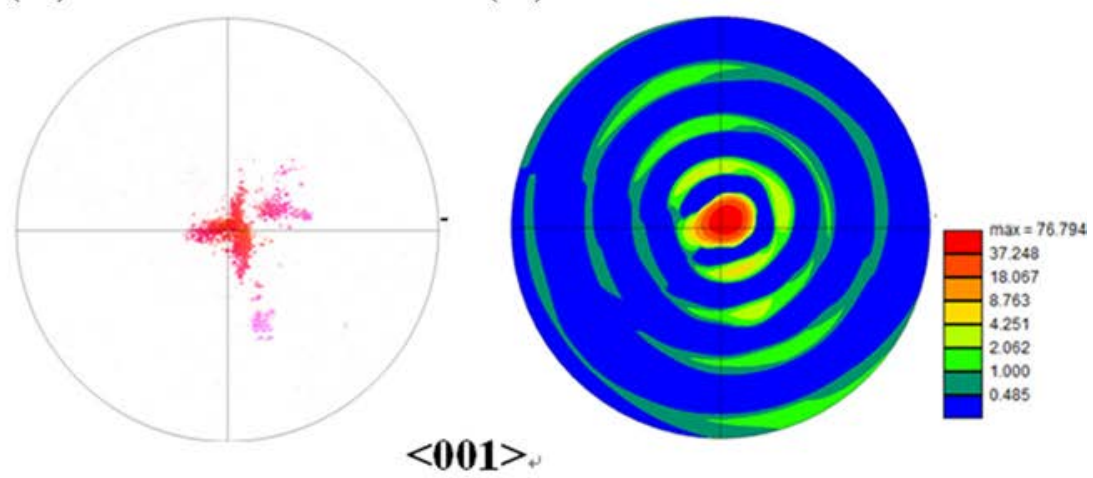

(c2)

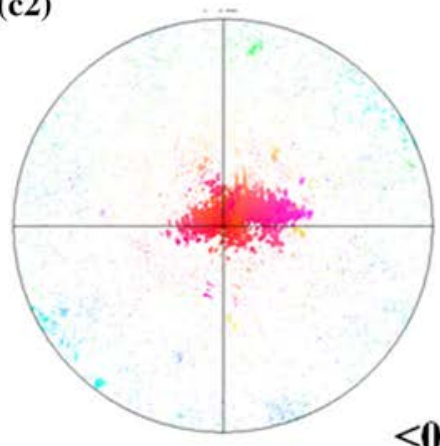

$<001>$ (c3)

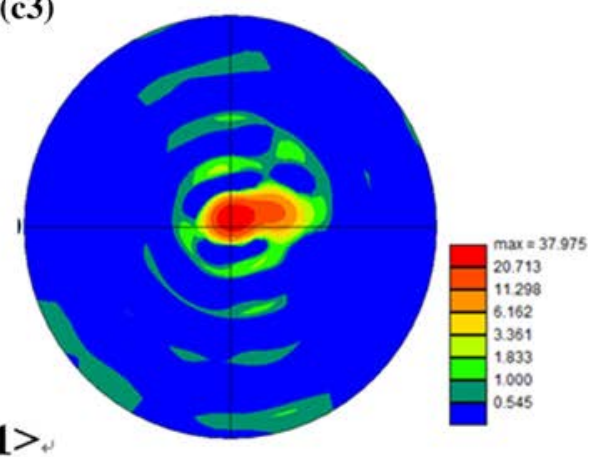

Fig. 14-EBSD maps and the corresponding pole figures for the longitudinal structures in the Al-12wtpctNi alloys solidified from $1023 \mathrm{~K}$ $\left(750{ }^{\circ} \mathrm{C}\right.$ ) at a cooling rate of $1 \mathrm{~K} / \mathrm{min}$ under a 12-T magnetic field: (a) EBSD maps and the corresponding $\langle 001\rangle$ pole figures for the $\mathrm{Al}_{3} \mathrm{Ni}$ phases; (b) EBSD maps and the corresponding $\langle 001\rangle$ pole figures for the $\mathrm{Al}_{3} \mathrm{Ni}$ phases in the magnified structure of $(a 1)$; (c) EBSD maps and the corresponding $\langle 001\rangle$ pole figures for the $\mathrm{Al}_{3} \mathrm{Ni}$ phases in the magnified structure of $(a 1)$.

where $\sigma_{\mathrm{L}}$ and $\sigma_{\mathrm{S}}$ are the electrical conductivities of the liquid and solid, respectively; $f_{\mathrm{L}}$ and $f_{\mathrm{S}}$ are the liquid and solid fractions, respectively; $S_{\mathrm{L}}$ and $S_{\mathrm{s}}$ are the thermoelectric (TE) power of the liquid and solid, respectively; and $G$ is the temperature gradient. Equation [4] indicates that the TE magnetic force (TEMF) acting on dendrites increases with the increase in the magnetic field intensity. This TEMF will break the dendrites when the magnetic field intensity is sufficiently high, as shown in Figure 16(b). As a consequence, the size of the $\mathrm{Al}_{3} \mathrm{Ni}$ phase will decrease, which in turn will contribute to the alignment of the dendrites. Thus, the $\mathrm{Al}_{3} \mathrm{Ni}$ primary phases will be aligned with the $\langle 001\rangle$ crystal direction along the magnetic field direction and form the layer-like structure shown in Figures 16(c), (e), and (f). In this study, it was observed that as the magnetic moment and the TEMF increased with the increase in the magnetic field, the alignment degree increased with the magnetic field (see Figures 8 and 9). Moreover, the alignment of the primary dendrites under the magnetic field occurred in the mushy zone during directional solidification (see Figure 16(e)). Thus, the longer the microstructure remained in the mushy zone, the more the field affected the microstructure. With the increase in 


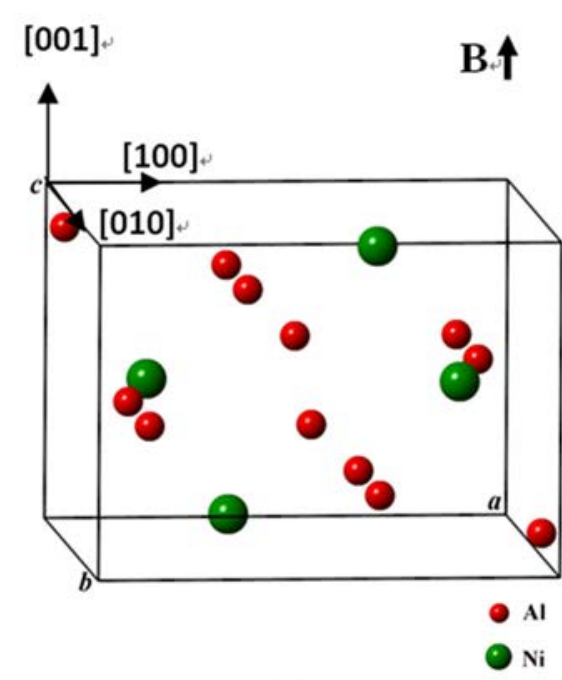

(a)

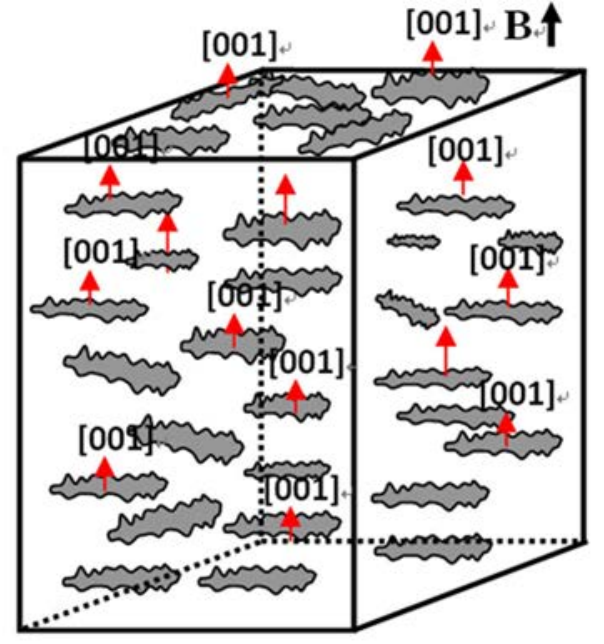

(b)

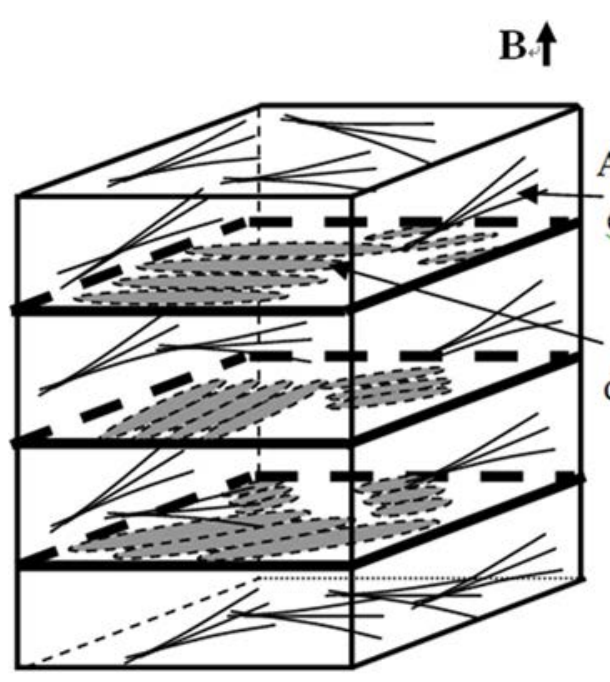

(c)

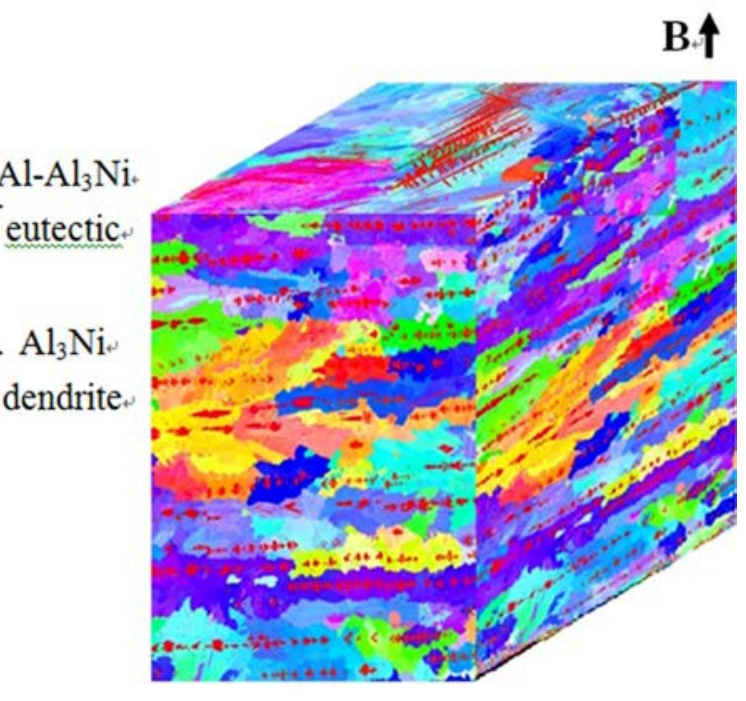

(d)

Fig. 15- Schematic illustration of the $\mathrm{Al}_{3} \mathrm{Ni}$ crystal structure and the alignment of the $\mathrm{Al}_{3} \mathrm{Ni}$ dendrites under a magnetic field: $(a)$ Al $l_{3} \mathrm{Ni}$ crystal structure; $(b)$ three-dimensional diagram of the structure in the mushy zone under the magnetic field; $(c)$ three-dimensional diagram of the structure below the eutectic isotherm under a magnetic field; $(d)$ three-dimensional EBSD maps for the structures below the eutectic isotherm in the Al-10wtpctNi alloy solidified from $1023 \mathrm{~K}\left(750^{\circ} \mathrm{C}\right)$ at a cooling rate of $18 \mathrm{~K} / \mathrm{min}$ under a 10 -T magnetic field.

the growth speed, the time the dendrites remained in the mushy zone decreased; therefore, the alignment degree decreased with the increase in the growth speed (see Figure 9(a)). The above-described results suggest that changing the angle between the solidification direction and magnetic field direction can control the crystallization process. Thus, any aligned material may be obtained by adjusting the angle between the magnetic direction and the solidification direction.

\section{Effect of a Magnetic Field on the Al-Al $\mathrm{H}_{3} \mathrm{Ni}$ Eutectic}

The above-described experimental results demonstrated that the application of a strong magnetic field modified the crystallographic orientation relationship in the $\mathrm{Al}-\mathrm{Al}_{3} \mathrm{Ni}$ eutectic in both eutectic and hypereutectic alloys. It is known that the preferred orientation relationship in the eutectics is mainly developed in one of two ways. In some instances, during the nucleation of the second phase, the epitaxial effects in the nucleation of the second phase on the first phase are important. In other cases, the most important effects are the changes in the crystallographic direction. ${ }^{[32]}$

The application of a strong magnetic field did not alter the orientation of the preferred growth direction of the $\mathrm{Al}_{3} \mathrm{Ni}$ eutectic fibers in the eutectic alloys, despite the remarkable magneto-crystalline anisotropy of the $\mathrm{Al}_{3} \mathrm{Ni}$ crystal (see Figure 12). For the Al phase with weak magneto-crystalline anisotropy, no alignment could be achieved, even under a 10-T magnetic field. ${ }^{[33]}$ Therefore, the change in the preferred orientation relationship in the $\mathrm{Al}-\mathrm{Al}_{3} \mathrm{Ni}$ eutectic under a strong magnetic field should not be attributed to the change in the crystallographic direction but to the effect of a strong magnetic 

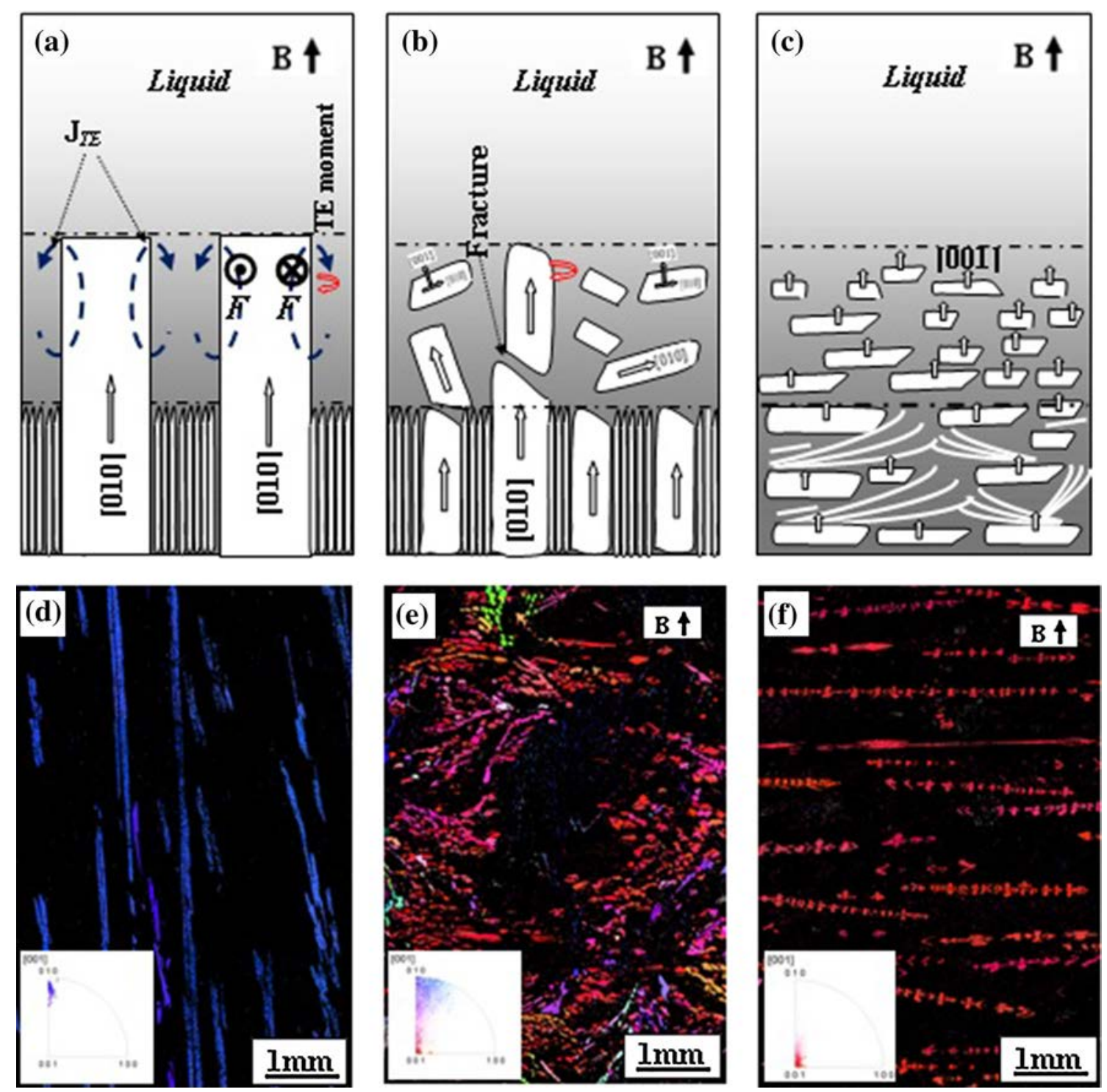

Fig. 16-Effect of the thermoelectric (TE) magnetic force and the magnetization force on an array of $\mathrm{Al}_{3} \mathrm{Ni}$ dendrites during directional solidification under an axial magnetic field: $(a)$ through $(c)$ schematic illustration of the TE magnetic force acting on the $\mathrm{Al}_{3} \mathrm{Ni}$ dendrites and the fracture and the alignment of the $\mathrm{Al}_{3} \mathrm{Ni}$ dendrites; $(d)$ EBSD map of the $\mathrm{Al}_{3} \mathrm{Ni}$ dendrites on the longitudinal structures without a magnetic field; $(e)$ and $(f)$ EBSD maps in the mushy zone and below the eutectic isotherm under a 10-T magnetic field, respectively.

field on epitaxial growth during the nucleation of the second $\mathrm{Al}$ phase on the leading $\mathrm{Al}_{3} \mathrm{Ni}$ phase. Compared with the $\mathrm{Al}-\mathrm{Al}_{2} \mathrm{Cu}$ eutectic, owing to the remarkable magneto-crystalline anisotropy of the leading $\mathrm{Al}_{2} \mathrm{Cu}$ phase, the $\mathrm{Al}-\mathrm{Al}_{2} \mathrm{Cu}$ eutectic was aligned under the applied magnetic field. ${ }^{[19]}$ This effect may be attributed to the content of the $\mathrm{Al}_{2} \mathrm{Cu}$ phase in the $\mathrm{Al}-\mathrm{Al}_{2} \mathrm{Cu}$ eutectic alloy being greater than the content of the $\mathrm{Al}_{3} \mathrm{Ni}$ phase in the $\mathrm{Al}-\mathrm{Al}_{3} \mathrm{Ni}$ eutectic alloy. It is not difficult to understand that with the increase in the content of the leading phase that possesses magneto-crystalline anisotropy in the eutectic, the magnetic force per unit volume imposed by the eutectic lamellae will increase. Therefore, the alignment behavior of the $\mathrm{Al}-\mathrm{Al}_{3} \mathrm{Ni}$ and
$\mathrm{Al}-\mathrm{Al}_{2} \mathrm{Cu}$ eutectics under a strong magnetic field is different. Thus, during the growth of the eutectic under a strong magnetic field, the magneto-crystalline anisotropy of the leading phase and its content in the eutectic will determine whether alignment will occur.

The modification of the orientation relationship of the $\mathrm{Al}-\mathrm{Al}_{3} \mathrm{Ni}$ eutectic in the hypereutectic $\mathrm{Al}-\mathrm{Ni}$ alloys under a strong magnetic field (see Figures 13(a2) and (d2)) should be attributed to the effect of the orientation of the $\mathrm{Al}_{3} \mathrm{Ni}$ primary phase on that of the $\mathrm{Al}_{3} \mathrm{Ni}$ eutectic fibers. The $\mathrm{Al}_{3} \mathrm{Ni}$ eutectic phase was the leading phase in the $\mathrm{Al}-\mathrm{Al}_{3} \mathrm{Ni}$ eutectic. The applied magnetic field was capable of aligning the $\mathrm{Al}_{3} \mathrm{Ni}$ primary phase and further modifying the orientation of the $\mathrm{Al}_{3} \mathrm{Ni}$ eutectic fibers 
(see Figure 14). As previously mentioned, changes in the crystallographic direction will modify the preferred orientation relationship in the eutectic. Therefore, the modification of the orientation relationship of the $\mathrm{Al}-\mathrm{Al}_{3} \mathrm{Ni}$ eutectic in the $\mathrm{Al}-\mathrm{Ni}$ hypereutectic alloy under the magnetic field should be attributed to the orientation of the $\mathrm{Al}_{3} \mathrm{Ni}$ eutectic fiber caused by the alignment of the $\mathrm{Al}_{3} \mathrm{Ni}$ primary phase under the magnetic field.

From the foregoing analysis, it can be concluded that the eutectic morphology will be mainly determined by external conditions (e.g., the heating flow extraction direction and the effect of the external conditions on the growth of the leading phase in the eutectic) and the internal properties of the eutectic (e.g., the growth anisotropy, the magneto-crystalline anisotropy, the effects of epitaxial growth during the nucleation of the second phase on the first phase, and the content of the leading phase in the eutectic).

\section{CONCLUSIONS}

The results of this study are summarized as follows:

1. The plane alignment of the $\mathrm{Al}_{3} \mathrm{Ni}$ phase square with the magnetic field occurred, and the $\langle 001\rangle$ crystal direction of the $\mathrm{Al}_{3} \mathrm{Ni}$ crystal became oriented along the magnetic field during both normal and directional solidification.

2. The alignment degree increased with the increase in the magnetic field and the decrease in the growth speed. Both the size of the $\mathrm{Al}_{3} \mathrm{Ni}$ phase and the layer spacing decreased with the increase in the growth speed.

3. The orientation of the preferred growth direction of the $\mathrm{Al}_{3} \mathrm{Ni}$ eutectic fiber depends on both the solidification direction and the alignment of the $\mathrm{Al}_{3} \mathrm{Ni}$ primary phase.

4. The alignment of the dendrite may be adjusted by changing the angle between the solidification and the magnetic field directions. Thus, any oriented material can be obtained.

\section{ACKNOWLEDGMENTS}

This work is supported partly by Bl-inter 0947 3220, National natural Science Foundation of China (Nos. 51171106 and 51271109) and the Program for Professor of Special Appointment (Eastern Scholar) at Shanghai Institutions of Higher Learning. The authors are indebted to Professor Thierry Duffar in SIMAP, Grenoble, for helpful and fruitful discussions.

\section{REFERENCES}

1. H. Morikawa, K. Sassa, and S. Asai: Mater. Trans. JIM, 1998, vol. 8, pp. 814-18.

2. T. Taniguchi, K. Sassa, and S. Asai: Mater. Trans. JIM, 2000, vol. 41, pp. 981-84.

3. M. Tahashi, K. Sassa, I. Hirabayashi, and S. Asai: Mater. Trans. $J I M$, 2000, vol. 41, pp. 985-90.

4. M. Ito, K. Sassa, M. Doyama, S. Yamada, and S. Asai: Tanso, 2000, vol. 191, pp. 37-41

5. X.W. Zhu, Y. Sakka, T.S. Suzuki, T. Uchikoshi, and S. Kikkawa: Acta Mater., 2010, vol. 58, pp. 146-61.

6. A.E. Mikelson and Y.K. Karklin: J. Cryst. Growth, 1981, vol. 52, pp. 524-29.

7. E.M. Savitisky, R.S. Torchinova, and S.A. Turanoy: J. Cryst. Growth, 1981, vol. 52, pp. 519-23.

8. P.D. Rango, M. Lee, P. Lejay, A. Sulpice et al:: Nature, 1991, vol. 349, pp. 770-72.

9. A. Katsuki, R. Tokunaga, and S.I. Watanabe: Chem. Lett., 1996, vol. 8, pp. 607-08.

10. K. Sassa, H. Morikawa, and S. Asai: J. Japan Inst. Met., 1997, vol. 12, pp. 1283-87.

11. H. Yasuda, I. Ohnaka, and Y. Yamamoto: Mater. Trans. JIM, 2003, vol. 44, pp. 2550-54.

12. X.Y. Lu, A. Nagata, K. Watanabe, T. Nojima, K. Sugawara, S. Hannda, and S. Kamada: Physica C, 2002, vol. 412, pp. 602-06.

13. C. Li, L. Chen, and Z. Ren: Rev. Sci. Instrum., 2012, vol. 83, art no. 043906.

14. Z. Sun, X. Guo, M. Guo, C. Li, J. Vleugels, Z. Ren, O. Van der Biest, and B. Blanpain: J. Phys. Chem. C, 2012, vol. 116, pp. 17676-81.

15. L.J. Fan, Y.B. Zhong, Y.L. Xu, Z. Shen, T.X. Zheng, and Z.M. Ren: J. Alloys Compd., 2015, vol. 645, pp. 369-75.

16. A. Croll, F.R. Szofran, P. Dold, K.W. Brez, and S.L. Lehoczky: J. Cryst. Growth, 1998, vol. 183, pp. 554-63.

17. T Alboussiere, R Moreau, and D Camel: Acad. Sci. Paris, 1991, vol. 313/II, pp. 749-55.

18. R. Moreau, O. Laskar, M. Tanaka, and D. Camel: Mater. Sci. Eng. A, 1993, vol. 173, pp. 93-100.

19. X. Li, Z.M. Ren, and Y. Fautrelle: J. Cryst. Growth, 2006, vol. 290, pp. 571-75.

20. X. Li, Y. Fautrelle, and Z.M. Ren: Acta Mater., 2007, vol. 55, pp. $5333-47$.

21. X. Li, Z.M. Ren, and Y. Fautrelle: Acta Mater., 2006, vol. 20, pp. $5349-60$

22. B. Cantor and G.A. Chadwick: J. Cryst. Growth, 1794, vol. 23, pp. 12-20.

23. G. Garmong: Metall. Trans., 1975, vol. 6A, pp. 1335-43.

24. I.G. Davies and D.D. Double: Solidification and Casting of Metals, The Metals Society, London 1979, p. 94.

25. X. Li, Y. Fautrelle, Z.M. Ren, Y.D. Zhang, and C. Esling: Acta Mater., 2010, vol. 58, pp. 2430-41.

26. I. Kittel: Introduction to Solid-State Physics, GIFML Publ. House, Moscow, 1963, p. 326.

27. T. Kimura: Proc. of Int. Symp. On Innovative Chemical Reaction Field (IMP 2002), The Society of Non-Traditional Technology, Tokyo, 2002, p. 1 .

28. H. Wang, Q.L. Wang, Z.M. Ren, and L.G. Yan: 2006 BIMW: 2006 Beijing International Materials Week, Pts 1-4, 2007, vols. 546-549, p. 1055.

29. C.J. Wang, Q. Wang, Z.Y. Wang, D.G. Li, K. Nakajima, and J.C. He: J. Cryst. Growth, 2008, vol. 310, pp. 1256-63.

30. J.A. Shercliff: J. Fluid Mech., 1979, vol. 91, pp. 231-51.

31. P. Lehmann, R. Moreau, D. Camel, and R. Bolcato: Acta Mater., 1998, vol. 46, pp. 4067-79.

32. M.C. Flemings: Solidification Processing, McGraw-Hill, New York, 1974, p. 115.

33. X. Li, Y. Fautrelle, and Z.M. Ren: Acta Mater., 2008, vol. 56, pp. 3146-61. 